\title{
Significance of vascular endothelial growth factor in growth and peritoneal dissemination of ovarian cancer
}

\author{
Samar Masoumi Moghaddam • Afshin Amini • \\ David L. Morris • Mohammad H. Pourgholami
}

Published online: 20 November 2011

(C) The Author(s) 2011. This article is published with open access at Springerlink.com

\begin{abstract}
Vascular endothelial growth factor (VEGF) is a key regulator of angiogenesis which drives endothelial cell survival, proliferation, and migration while increasing vascular permeability. Playing an important role in the physiology of normal ovaries, VEGF has also been implicated in the pathogenesis of ovarian cancer. Essentially by promoting tumor angiogenesis and enhancing vascular permeability, VEGF contributes to the development of peritoneal carcinomatosis associated with malignant ascites formation, the characteristic feature of advanced ovarian cancer at diagnosis. In both experimental and clinical studies, VEGF levels have been inversely correlated with survival. Moreover, VEGF inhibition has been shown to inhibit tumor growth and ascites production and to suppress tumor invasion and metastasis. These findings have laid the basis for the clinical evaluation of agents targeting VEGF signaling pathway in patients with ovarian cancer. In this review, we will focus on VEGF involvement in the pathophysiology of ovarian cancer and its contribution to the disease progression and dissemination.
\end{abstract}

S. Masoumi Moghaddam • A. Amini • M. H. Pourgholami $(\bowtie)$ Cancer Research Laboratories, Department of Surgery, St George Hospital, University of New South Wales, Sydney, NSW 2217, Australia

e-mail: mh.pourgholami@unsw.edu.au

S. Masoumi Moghaddam

e-mail: s.masoumimoghaddam@student.unsw.edu.au

A. Amini

e-mail: a.amini@unsw.edu.au

D. L. Morris

Department of Surgery, St George Hospital,

University of New South Wales,

Sydney, NSW 2217, Australia

e-mail: david.morris@unsw.edu.au
Keywords Angiogenesis · Bevacizumab · Malignant ascites - Ovarian cancer P Peritoneal carcinomatosis . Vascular endothelial growth factor

\section{Introduction}

Vascular endothelial growth factor (VEGF), a potent cytokine and a key regulator of physiological and pathological angiogenesis, has a major contribution to diverse pathological processes, in particular tumorigenesis [1]. In women, an exceptional role is played by VEGF through its involvement in ovarian biology. Closely linked to the normal function of ovaries, VEGF is also implicated in ovarian pathologies, including malignant neoplasms [2]. Ovarian cancer, the seventh leading cancer in women and the second cause of death from gynecologic malignancies worldwide [3], is a richly vascularized tumor that is known to be highly dependent on VEGF-mediated angiogenesis [4]. While representing a crucial, early event in ovarian carcinogenesis [5], VEGF expression is associated with tumor growth and aggression, as well as poor survival [6-8].

Peritoneal seeding is the most common pathway for the spread of ovarian cancer [9]. At diagnosis, about two thirds of the patients with ovarian cancer have already developed peritoneal carcinomatosis [10] and more than one third present with malignant ascites [11]. Both tumor burden and ascites are inversely associated with survival $[12,13]$. Basically through promoting tumor angiogenesis and enhancing the vascular permeability, VEGF has been implicated in the peritoneal dissemination of ovarian cancer and the subsequent development of malignant ascites, further highlighting the key importance of VEGF in the pathophysiology of the disease. Here, we review different aspects of VEGF contribution to ovarian cancer, address VEGF-targeted strategies as a 
therapeutic approach to the disease, and present the latest clinical data on the subject.

\section{Vascular endothelial growth factor}

\subsection{Identification}

In 1983, the identification of a polypeptide from the conditioned medium of a guinea pig tumor cell line was reported by Senger et al. [14]. To reflect its role in enhancing the permeability of tumor vasculature, they designated this polypeptide "vascular permeability factor (VPF)." Later in 1989, Ferrara and Henzel [15] isolated a potent endothelial mitogen from the conditioned media of bovine pituitary follicular cells and named it vascular endothelial growth factor to show its specificity for endothelial cells. In the same year and based on the work by Senger et al., the isolation and sequencing of human VPF from U937 cells were independently reported by Connolly et al. [16]. Following cDNA cloning of VEGF and VPF, it was eventually revealed that these molecules were the same $[17,18]$.

\subsection{VEGF and its receptors}

VEGF family include VEGF-A (hereafter VEGF), VEGFB, VEGF-C, VEGF-D, placenta growth factor (PlGF), VEGF-E (viral VEGF homologs), and VEGF-F (snake venom VEGFs) [19]. VEGF is a $45-\mathrm{kDa}$ heparin-binding homodimeric glycoprotein [15]. At least 14 various isoforms of VEGF result from alternative splicing [20]. $\mathrm{VEGF}_{165}$ is the most abundant and mitogenic isoform which exists as both extracellular matrix-bound and freely diffusible protein. Plasmin and various metalloproteinases can split the bound fraction into bioactive fragments $\mathrm{VEGF}_{110}$ or $\mathrm{VEGF}_{113}$ [21]. VEGF ${ }_{121}$ is a freely diffusible protein that does not bind to heparin. $\mathrm{VEGF}_{189}$ and $\mathrm{VEGF}_{206}$ are longer, heparin-binding isoforms which might also undergo extracellular proteolysis to generate bioactive, diffusible fragments [22]. Thus, VEGF proteins may become available to endothelial cells by at least two different mechanisms: alternative splicing and proteolytic cleavage. Besides, differential ability of VEGF isoforms in binding to the extracellular matrix generates an "angiogenic gradient" that is now considered of importance in a variety of pathophysiological conditions [23].

VEGF binding sites include three receptor tyrosine kinases (RTK) called vascular endothelial growth factor receptor (VEGFR)-1, VEGFR-2, and VEGFR-3 (Fig. 1). VEGF family members show differential affinity for their receptors. VEGF, VEGF-B, and PIGF can bind and activate VEGFR-1, whereas VEGFR-2 is primarily activated by
VEGF, and VEGFR-3 activation is only triggered by VEGF-C and VEGF-D [24].

Neuropilins (NRPs) have also been implicated in VEGFR activation [25]. In endothelial cells, NRP-1 is thought to act primarily as a co-receptor for VEGF- $\mathrm{A}_{165}$ by forming complexes with VEGFR-2. VEGFRs were identified initially on the cell surface of vascular endothelial cells $[26,27]$ and, subsequently, on bone marrow-derived cells such as monocytes [28]. VEGFR-1 expression has been observed in vascular endothelial cells and a range of nonendothelial cells including hematopoietic stem cells, monocytes, and macrophages [29]. VEGFR-2 is expressed in vascular endothelial cells and, at lower levels, in neurons, osteoblasts, pancreatic duct cells, retinal progenitor cells, and megakaryocytes [30]. VEGFR-3 expression seems to be largely restricted to lymphatic endothelial cells [31]. VEGFRs, like other RTKs, become activated when ligand-receptor binding and resultant dimerization happen. Subsequent autophosphorylation on certain tyrosine residues triggers intracellular signaling cascade mediated by several effectors. Although VEGFR-1 affinity for VEGF is tenfold higher than that of VEGFR-2, VEGF activation of VEGFR-2 is much more significant. Thus, VEGFR-2 represents the major mediator of VEGF-driven responses in endothelial cells promoting angiogenesis and vascular permeability [21].

\subsection{Biological effects of VEGF}

VEGF biologically affects angiogenesis, hematopoiesis, hemodynamics, and vascular homeostasis. VEGF drives endothelial cell survival, proliferation, migration, and tube formation. Anti-apoptotic activity of VEGF is in part mediated through the activation of PI3K/Akt pathway [32]. VEGF also prevents endothelial apoptosis by inducing the expression of apoptosis-regulating proteins such as Bcl2, A1 [33], XIAP, and survivin [34]. Acting as an endothelial cell mitogen [35], VEGF promotes sprouting of vascular endothelial cells during physiological and tumor angiogenesis. In addition, VEGF controls hematopoietic stem cells' survival during hematopoietic repopulation and plays an important role in regulating the differentiation of endothelial progenitor cells and their migration to regions of neoangiogenesis in adults [1]. Moreover, VEGF enhances vascular permeability to water and large molecular weight proteins [36], a process in which p38 MAPK pathway has been implicated as an essential mediator [37]. VEGF also stimulates nitric oxide-mediated vasodilatation [38]. VEGF, at low physiological levels, maintains vascular homeostasis in vascularized tissues, especially in fenestrated and sinusoidal vessels in endocrine and secretory organs as well as large blood vessels, skeletal muscle, and myocardium [39]. 


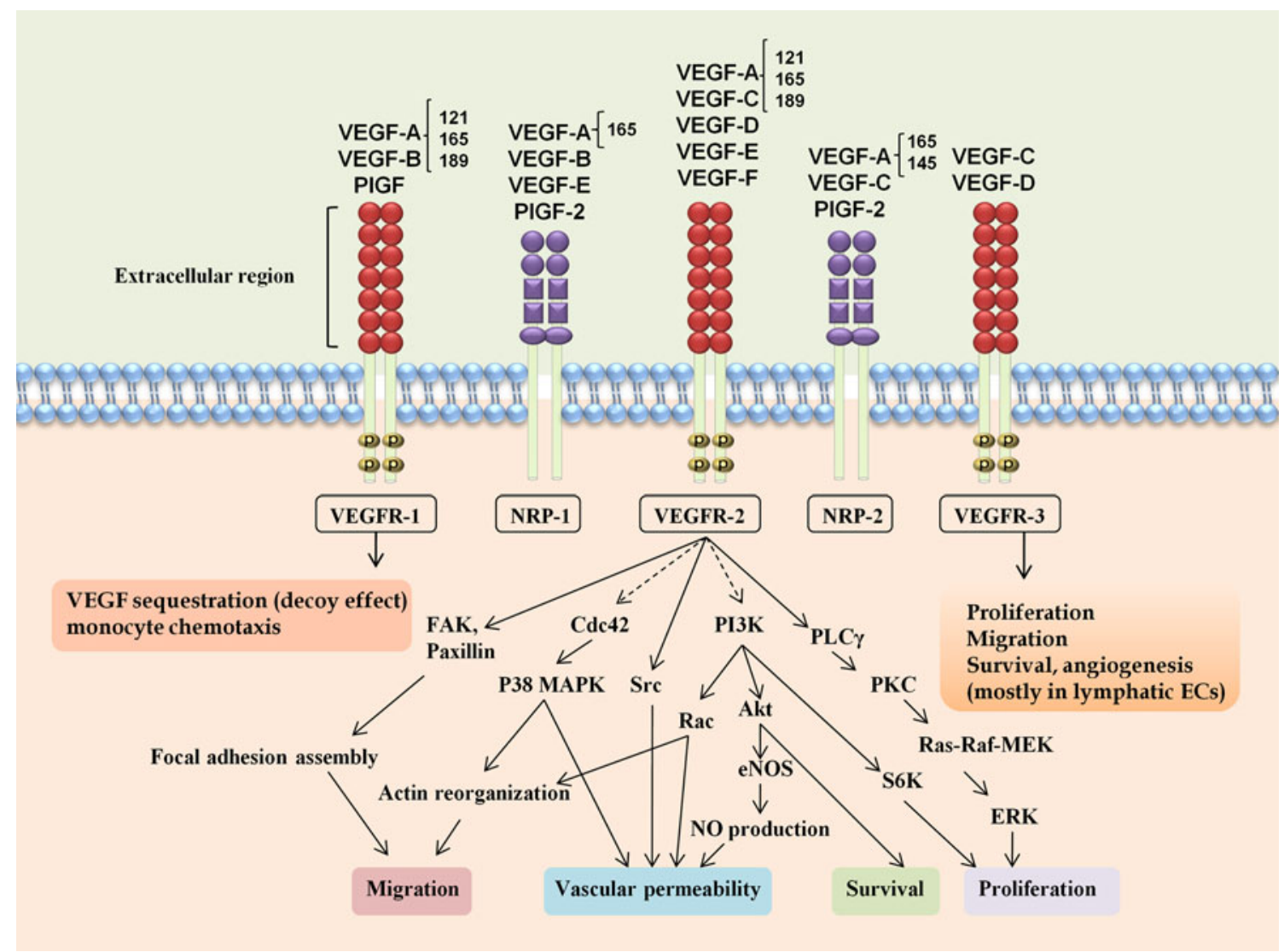

Fig. 1 Vascular endothelial growth factor (VEGF) family and their receptors. VEGF family members bind to specific receptor tyrosine kinases VEGFR-1, VEGFR-2, and VEGFR-3 and, through activating different cascades, exert their various biologic effects. VEGFR-2

\subsubsection{VEGF and physiological processes}

VEGF promotes physiological angiogenesis activated in embryonic and postnatal development, skeletal growth, and endochondral bone formation [40]. Apart from its unique contribution to ovarian physiology described below, VEGF mediates other angiogenic processes in adults, such as wound healing [41, 42], tissue regeneration after injury and ischemia [43, 44], and exercise-induced angiogenesis in skeletal muscle [45].

The ovary is distinct from other endocrine organs in that it undergoes repetitive cycles of angiogenesis within its various glandular compartments [46]. VEGF expression and production within the ovary are critical for normal reproductive function [2]. Increased intrafollicular VEGF has been shown during the initial part of the ovulatory cycle, with peak concentrations just before the start of the luteal phase [47]. By driving thecal vascularization, VEGF supports the cyclic growth, development, and maturation of the follicle; ovulation; and associated endocrine changes. Consistently, VEGF inhibition in different stages of follicular phase can disrupt these normal events [46, 48- represents the major mediator of VEGF-driven responses in endothelial cells responsible for most VEGF angiogenic activities. Neuropilins (NRP-1 and NRP-2) are known as co-receptors for VEGF

52]. As a permeability factor, VEGF is proposed to modulate differential vascular permeability leading to the preferential accumulation of gonadotropins within the dominant follicle, hence its likely involvement in the process of follicular selection [2]. In addition, VEGF might mediate the preovulatory increase in follicular vascular permeability and the resulting edema, a mechanism contributing to ovulation [53]. VEGF is also essential for corpus luteum angiogenesis [54] as inhibition of VEGF has a profound inhibitory effect upon luteal function [55]. Coexpression of VEGF and its receptors by granulosa cells has attributed another potentially important function to VEGF [56]. It has been suggested that VEGF may directly modulate the function of these cells by promoting cell survival [57], proliferation [56, 58], and/or migration [59].

\subsubsection{VEGF in nonmalignant disorders}

VEGF has been implicated in various pathological conditions. Besides performing stabilizing functions in the developing retinal vasculature [60], VEGF has strikingly been correlated with intraocular neovascular syndromes 
such as retinopathy of prematurity [61], diabetic retinopathy [62], central retinal vein occlusion [63], and neovascular age-related macular degeneration [64]. It has also been shown that VEGF may be an important mediator of such inflammatory disorders as psoriasis [65], rheumatoid arthritis [66], osteoarthritis [67], human renal [68] and cardiac [69] allograft rejection, as well as blood-brain barrier breakdown and the resulting edema in acute brain injury[70]. In addition, VEGF contribution to some cardiovascular diseases has been reported, including infantile hemangiomas [71], atherosclerosis [72], ischemic heart disease [73], peripheral vascular disease [74], and focal cerebral ischemia [75]. Moreover, different investigations have implicated VEGF in the pathology of female reproductive tract, such as polycystic ovary syndrome, ovarian hyperstimulation syndrome [76], endometriosis [77], and preeclampsia [78, 79]. Besides, VEGF insufficiency might contribute to neurodegeneration, respiratory distress and, possibly, cardiac failure [80].

\subsubsection{Role of VEGF in malignancies}

VEGF and its receptors are expressed in the vast majority of human solid tumors, including those of the lung [81], breast [82], gastrointestinal tract [83], kidney, bladder [84], ovary, endometrium [85], brain [86], and endocrine system [87]. In addition to tumor cells as the major source of VEGF, stromal cells such as monocytes, macrophages, and fibroblasts also produce VEGF [88, 89]. VEGF contributes to tumor vascularization, progression, and invasion. To grow beyond microscopic size, tumors need to undergo an "angiogenic switch" to enter a vascular phase in which blood perfusion provides a better delivery of oxygen and nutrients and an enhanced disposal of waste products [90]. VEGF is a key mediator of this early event in tumor angiogenesis [91]. Additionally, the endothelial cells of intratumoral vasculature are more dependent on VEGF as a survival factor and mitogen than those of normal vasculature elsewhere [92]. VEGF-induced enhancement of endothelial cell survival, proliferation, and migration together with the resulting synthesis of other pro-angiogenic factors, including basic fibroblast growth factor, heparin-binding epidermal growth factor (EGF)-like growth factor, granulocyte colony-stimulating factor, insulin-like growth factor1, interleukin (IL)-6, and IL-8, provides a sustainable angiogenesis [93, 94].

Moreover, VEGF helps tumor stroma form and mature. By augmenting the permeability of the microvasculature, VEGF promotes extravasation of plasma proteins and water into the tumor milieu and the subsequent reshaping of extracellular matrix that makes it favorable to migration and proliferation of endothelial cells, monocytes, macrophages, and fibroblasts. This allows final degradation of the provisional matrix, which will be then replaced with fibroblast-produced proteins, proteoglycans, and glycosaminoglycans [95]. VEGF activation of matrix-degrading enzymes allows unhindered development of further blood vessels [96].

VEGF is a crucial factor in tumor invasion and metastasis as well. While tumor vascularization is a prerequisite for tumor cells to spread by shedding into the circulation, the newly formed, immature capillaries with fenestrated basement membrane allow greater accessibility for tumor cells [97]. VEGF has also been shown to enhance tumor invasion through a direct, autocrine effect on tumor cells $[35,98,99]$. Besides, VEGF helps the growing tumor evade host immune responses via inhibiting functional maturation of dendritic cells $[100,101]$, the most potent antigen-presenting cells with a central role in antitumor cell-mediated immunity. Additionally, VEGF stimulates hematopoietic progenitor cells to initiate the pre-metastatic niche, a regulatory event in tumor metastasis abolished by VEGF inhibition [102].

VEGF contribution to malignancies is not exclusive to solid tumors. VEGF is expressed in a wide variety of cell lines derived from hematological neoplasms, including $\mathrm{T}$ cell lymphoma, acute lymphoblastic leukemia, Burkitt's lymphoma, acute lymphocytic leukemia, histiocytic lymphoma, and promyelocytic leukemia [103]. Survival, proliferation, and migration of leukemia/lymphoma cells can be stimulated by autocrine and paracrine VEGF loops. VEGF/VEGFR-related pathways are thought to present a promising therapeutic target in some hematolymphoid malignancies [104].

\section{VEGF and pathogenesis of ovarian cancer}

The association of VEGF and ovarian cancer has been documented in several studies. Constitutive VEGF gene expression in normal and neoplastic human ovaries [105] as well as its differential expression in tumor specimens compared to benign ovarian tissue [106, 107] has been reported. Preclinical experiments have shown that overexpression of VEGF can transform normal, functional ovarian epithelium into ascites-producing, neoplastic tissue $[4,108]$. Large amounts of VEGF are secreted in ovarian cancer in vitro and in vivo [109]. Overexpression of intratumoral VEGF, found to correlate with poorer prognosis $[8,110,111]$ and enhanced odds of progression [112], has been suggested as an independent prognostic factor for overall survival [113]. VEGF expression within omental metastases appeared not only correlated with the extent of omental involvement but also as an independent prognostic indicator [114]. Elevated levels of VEGF were detected in fluid samples from malignant cysts generated during 
ovarian cancer development which may represent a useful biomarker of angiogenesis and tumor progression [106, 107]. VEGF levels in ovarian cancer-induced malignant ascites are markedly elevated compared with those in ascitic fluids of nonmalignant origin [115] being reportedly of prognostic significance [116]. VEGF has been suggested as a serological biomarker for clinical diagnosis and a predictor of prognosis in patients with ovarian cancer [117119]. In addition, overexpression of VEGF receptors [106] and co-receptors $[120,121]$ has been found in ovarian cancer. It has been reported that VEGF gene polymorphisms are an independent adverse prognosticator of overall survival [122].

VEGF expression and/or production in ovarian cancer is induced not only by hypoxia [123-125] but also by different growth factors, mediators, and effectors, including insulin-like growth factor 1 [126], EGF [127], plateletderived growth factor (PDGF) [128], transforming growth factor- $\beta$ [129], tumor necrosis factor- $\alpha$ (TNF- $\alpha)$ [130], TNF-like weak inducer of apoptosis [131], IL-1 $\beta$ [132], IL6 [133], endothelin-1 [134, 135], prostaglandine E2 [136], gonadotropins [137, 138], 4-hydroxy estradiol [139], matrix metalloproteinases (MMPs) [140], reactive oxygen species [141], and cyclooxygenase [142, 143]. Additionally, lysophosphatidic acid (LPA), a bioactive phospholipid present in high levels in the ascitic fluid and plasma from ovarian cancer patients, has proved to induce VEGF expression in ovarian cancer cells [144], a process in which NF-KB pathway has been recently implicated [145]. Moreover, oncogenes such as PIK3CA [146] and Her-2/neu [147] have been indicated to regulate VEGF production in ovarian cancer cells. Here, we review different aspects of VEGF implication in the pathogenesis of ovarian cancer.

\subsection{VEGF, carcinogenesis, and tumor growth in ovarian cancer}

The theory of incessant ovulation hypothesizes that repetitive wounding of the ovarian surface epithelium and cell proliferation in postovulatory repair result in a stepwise accumulation of genomic abnormalities. Ovarian epithelial inclusion cysts occur as a result and might increase risk of carcinogenesis by trapping cells in an environment of aberrant autocrine or paracrine stimulation by growth factors including VEGF which activate intracellular processes and signaling pathways [148].

Initial studies revealed that VEGF-driven angiogenesis is an early, crucial event in ovarian carcinogenesis $[5,106]$ and implicated VEGF-regulated angiogenesis as an important component of ovarian cancer growth $[6,149]$. Schiffenbauer et al. attributed angiogenic potential of ovarian cancer to gonadotropin-induced expression of VEGF [137]. Later, Zhang et al. showed that VEGF derived from ovarian cancer cells upregulates angiopoietin 2 in host endothelial cells and induces in a paracrine manner the remodeling of host vasculature to support angiogenesis during tumor growth [150]. Besides, it has been indicated that Akt1 and Akt3, two downstream effectors of PI3K signaling pathway, have their important roles in ovarian tumorigenesis played via regulation of VEGF secretion and angiogenesis [151, 152]. Moreover, Kryczek et al. showed that tumor-derived VEGF and CXCL12 formed a synergistic angiogenesis axis critical for tumor neovascularization in human ovarian cancer [125].

Through locating VEGFR-2 on ovarian cancer cells coexpressed along with VEGF, Boocock et al. raised the possibility that an autocrine loop might directly enhance the tumor growth [153]. This has been further validated by other investigators. Mattern and colleagues showed the close correlation of VEGF expression with tumor cell proliferation [154]. Chen et al. indicated significant correlations between the expression levels of VEGF, VEGFR1, and VEGFR2 in ovarian cancer cells and the activation status of signal transducer and activator of transcription pathway (STAT3 and STAT5) in ovarian cancer cells [155]. Distinct VEGFR-2-mediated pathways promoting tumor growth by directly acting on ovarian cancer cells have been demonstrated [156-158].

\subsection{VEGF and ovarian cancer dissemination}

Primary tumor cell with its production of a unique array of growth factors, in particular VEGF, specifically dictates the pattern of tumor spread [159]. Kaplan et al. showed that the media conditioned by a tumor type, high in both PlGF and VEGF, was able to reprogram the metastatic profile of another tumor type, high in VEGF but low in PIGF [102]. They demonstrated that VEGF activation of VEGFR-1 ${ }^{+}$ progenitor cells allows them to home to tumor-specific premetastatic sites before the arrival of tumor cells. VEGF also stimulates the migration of monocytes or macrophages that further support the tumor stromal microenvironment [160]. In addition, tumor angiogenesis leads to the formation of structurally abnormal blood vessels with fragmented, leaky basement membranes which are easily penetrated by tumor cells [161]. Moreover, Weis et al. demonstrated that Src family kinases, playing a specific and vital role in ovarian cancer [162], can be activated by VEGF that leads to a breakdown in the endothelial barrier function which in turn hastens tumor cell extravasation at metastatic sites [163]. They observed that lung colonization of ovarian tumor cells enhanced by VEGF was alleviated by VEGF inhibitors.

VEGF contributes to ovarian cancer progression through promoting angiogenesis as well as enhancing vascular permeability leading to malignant effusion, as described below. VEGF implication in ovarian cancer invasion and metastasis has been well established by different studies. 
Through demonstrating VEGF expression in normal and neoplastic human ovaries and identifying the malignant ovarian epithelium as one source of ascitic VEGF, Olson et al. implicated VEGF as an important mediator of ascites formation and tumor metastasis in ovarian cancer [105]. They later showed that in vivo neutralization of VEGF inhibits ovarian cancer-associated ascites formation and tumor growth [164]. Mu and colleagues [6] indicated that growth/metastasis of ovarian cancer cells correlates with their VEGF-producing capacity and that angiogenesis inhibition hampers tumor growth and metastasis through mechanisms including the suppression of VEGF function in vivo. Ovarian cancer cells overexpressing VEGF hold a metastatic advantage over those lacking VEGF [163, 165]. $\mathrm{Li}$ et al. measured significantly higher levels of serum VEGF in patients with metastasis as compared to metastasis-free patients [118]. VEGF has also been implicated in ovarian cancer dissemination via interacting with tumor microenvironment. So et al. showed that LPA induction of ovarian cancer invasion and migration is mediated by VEGFR-2, leading to the secretion and activation of MMP-2 and urokinase type plasminogen activator [166]. VEGF regulation of ovarian cancer invasion and migration through VEGFR-mediated secretion and activation of MMP-2, MMP-7, and MMP-9 has been indicated in vitro $[167,168]$. Matei et al. suggested a correlation between PDGF and VEGF networks in ovarian cancer cells and tumors in a way that PDGF blockade and the resultant inhibition of VEGF might affect the tumor microenvironment which is detrimental to tumor progression [128]. Belotti and colleagues implicated a complex cross talk between VEGF and MMPs in ovarian cancer progression and invasion [169]. Wang and others proposed a functionally significant role for VEGF in vasculogenic mimicry, the formation of a fluid-conducting, matrix-rich meshwork critical for a tumor blood supply associated with aggressive and metastatic features [170]. They concluded that this part is taken through VEGF upregulation of EphA2 and final activation of MMPs. VEGF might also contribute to ovarian cancer metastasis by directly stimulating proliferation, survival, and/or migration of tumor cells [171]. VEGF also allows ovarian cancer cells to evade immune response. It has been demonstrated that VEGF directly suppresses $\mathrm{T}$ cell activation [172] and that its levels in ascitic fluid are inversely correlated with immunologically important $\mathrm{T}$ cell subpopulations [116].

\subsubsection{Role of VEGF in intraperitoneal dissemination of ovarian cancer}

At peritoneal metastasis, primary tumors - generally confined to the ovaries - shed tumor cells into the peritoneum. Malignant cells, often forming cellular aggregates or sphe- roids, are then transported throughout the peritoneal cavity and subsequently implant on the peritoneal wall, gastrointestinal tract, omentum, and diaphragm. Figure 2 illustrates a proposed model for intraperitoneal dissemination of ovarian cancer $[173,174]$. It has been suggested that intraperitoneal fluid and peritoneal surface motion (peristalsis) are prominent mechanisms controlling the patterns of spread [175]. This "seeding" of the peritoneum and the resultant peritoneal carcinomatosis are the most widely recognized behaviors of ovarian cancer that is frequently associated with ascites formation $[4,171]$. Peritoneal carcinomatosis is a frequent cause of death in patients with primary advanced or recurrent ovarian cancers $[176,177]$, the extent of which is a predictor of tumor resectability and the disease prognosis [178].

Malignant ascites is a manifestation of end-stage disease in a variety of cancers, among which ovarian cancer has reportedly been the predominant cause [179-182]. Malignant ascites arises from both tumor surface and tumor-free peritoneum [183]. This metastatic pattern is dependent on establishing new blood vessels at the newly seeded site [4]. VEGF contributes to intraperitoneal dissemination of ovarian cancer by promoting neovascularization and enhancing vascular permeability leading to the subsequent growth of intraperitoneal tumors, development of peritoneal carcinomatosis, and formation of malignant ascites [184, 185]. Ovarian cancer cells [105] along with peritoneal mesothelial cells have been identified as possible sources of ascitic VEGF [132]. The role of VEGF in the peritoneal metastasis of ovarian cancer has been explored by different investigators. Senger et al. initially described VEGF as a tumor-secreted vascular permeability factor which promotes accumulation of ascites fluid $[14,186]$. Yeo et al. later showed that high VEGF concentrations correlate with tumor cell growth and ascites fluid accumulation in experimental guinea pig tumors [187]. Using animal models of peritoneal carcinomatosis, it has been demonstrated that overexpression of VEGF leads to an increase in tumor and peritoneal-associated neovasculature and increased peritoneal vascular permeability [188, 189]. Thus, ascites accumulation is increased not only indirectly by allowing tumor growth through stimulation of angiogenesis but also directly through its ability to increase the peritoneal vasculature permeability [190]. Byrne et al. [184] reported that enforced expression of VEGF by ovarian cancer cells dramatically reduced the time to onset of ascites formation and that even tumor-free peritoneal overexpression of VEGF was sufficient to cause ascites to accumulate. Mesiano and colleagues [149] indicated that tumorderived VEGF played a pivotal role in the development of malignant ascites from ovarian cancer. However, they raise the possibility that intraperitoneal carcinomatosis has an angiogenesis-dependent component represented by the larger solid intraperitoneal tumors in need of neovasculari- 


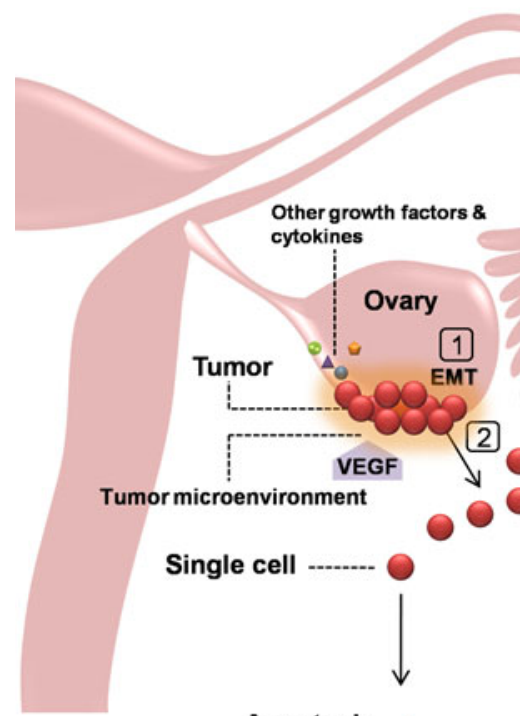

Apoptosis =
Fig. 2 A proposed model for intraperitoneal dissemination of ovarian cancer $[173,174]$ with focus on the role of VEGF. Primary tumors are generally confined to the ovaries. To metastasize, tumor cells undergo epithelial-mesenchymal transition (EMT) to attain motility 1 Subsequently, ruptured tumor sheds malignant cells into the peritoneum 2 where they often form spheroids to survive. 3 Spheroids undergo changes into invasive mesenchymal phenotype to maintain survival and motility. 4 These cellular aggregates are transported throughout the peritoneal cavity by normal peritoneal fluid and then adhere to and implant on the peritoneum and mesothelial linings of pelvic and

zation for continued growth and an angiogenesisindependent component including the thin layers of tumor and some of the smaller solid buds surviving by passive diffusion of nutrients from the underlying host vasculature and the surrounding peritoneal fluid. Moreover, VEGF inhibition hampered the formation of malignant ascites and the progressive growth of peritoneal tumors in ovarian cancer-bearing mice [191, 192]. Similarly, we have shown in a murine model of ovarian cancer with peritoneal carcinomatosis that plasma and, in particular, ascitic VEGF levels correlate well with malignant ascites formation and that VEGF inhibition dramatically halts ascites production [185]. Liao et al. have recently reported that TGF-b blockade in an experimental model of ovarian cancer inhibited ascites production via inhibition of VEGF production [129]. Dong and others proposed that elevated levels of VEGF in ascites might be useful in differentiating benign from malignant ascites [193]. In addition, an antiapoptotic role for VEGF in protection of the ovarian cancer cells shed into ascetic fluid has been suggested by Sher et al. [157]. They implicated an autocrine VEGF/VEGFR-2 loop in protecting ovarian cancer cells from apoptosis under anchorage free growth conditions (anoikis). abdominal organs 5 , where they undergo a reverse transition (MET) 6 and disaggregation 7 to initiate metastatic growth. Through the activity of MMPs, matrix degradation occurs 8 and invasive tumor cells infiltrate the mesothelial lining and the extracellular matrix 9. Cytokines and growth factors, such as VEGF, TNF- $\alpha$, IL-6, IL-8, and bFGF, contribute to EMT and invasiveness of spheroids via autocrine and paracrine loops. VEGF is also significantly involved in different steps of the process, including primary tumor angiogenesis, neovascularization at newly seeded sites, MMP-mediated matrix degradation, and malignant ascites formation

Moreover, interplay between VEGF and MMPs in the peritoneal spread of ovarian cancer has been studied in different investigations. Yabushita et al. reported an association between the VEGF levels and the expression and activation of MMP-2 which they implicated in the progression of the peritoneal involvement [194]. Belotti and others indicated that MMPs, mainly MMP9, contributed to the release of biologically active VEGF and consequently to the formation of ascites [140]. Conversely, VEGF stimulated host expression of MMP-9 in an organ-specific manner, and VEGF inhibition reduced VEGF-induced MMP9 expression while halting ascitic liquid formation and intraperitoneal tumor burden [169].

\subsubsection{Extraperitoneal metastasis of ovarian cancer}

Upon diagnosis, metastases outside of the peritoneal cavity are rare in ovarian cancer, and the disease is usually confined to the peritoneal cavity at presentation. However, extraperitoneal dissemination through lymphatics and blood stream is increasingly recognized during treatment [195]. The pleural cavity is the most common extraperitoneal site to which stage IV epithelial ovarian cancer 
preferentially metastasizes [196]. The liver and lung are other common sites of metastasis. VEGF contribution to ovarian metastasis of the lymph nodes, lung, and liver has been reported $[6,163]$. VEGF-C, another member of the VEGF family, has been implicated in lymphatic spread of ovarian cancer [197].

\section{VEGF/VEGFR-targeted therapy in ovarian cancer}

Based on the major role played by VEGF in the pathogenesis of ovarian cancer along with the promising preclinical results, agents targeting VEGF signaling pathways have been under clinical investigation for activity in ovarian cancer (Table 1).

\subsection{VEGF neutralization}

Known as the first anti-VEGF agent approved by Food and Drug Administration in 2004 for clinical use in colorectal cancer, bevacizumab has been the first and most studied anti-VEGF agent in clinical evaluation for ovarian cancer. Bevacizumab is a recombinant humanized VEGF monoclonal antibody derived from its murine equivalent A4.6.1 that targets all active isoforms of VEGF, preventing them from binding to VEGFRs [198]. In initial reports, Mesiano et al. demonstrated that A4.6.1 inhibited subcutaneous and intraperitoneal tumor growth and completely prevented ascites production in an athymic mouse model of ovarian cancer [149]. The same group later reported additive or synergistic effects of this antibody in combination therapy as enhanced sensitivity to paclitaxel and marked reduction of tumor growth and ascites formation [199]. Using a murine ovarian cancer model, Mabuchi et al. reported significant antitumor activity of bevacizumab as a single agent or in combination with cisplatin and concluded that it might also prolong survival when used as maintenance therapy after a complete response to cisplatin-based chemotherapy [200]. Preclinical studies employing VEGF immunoneutralization laid the basis for clinical evaluation of bevacizumab in ovarian cancer. Table 2 summarizes the accessible results from some of these investigations.

Aflibercept (VEGF trap) [201] is a soluble decoy receptor that binds and inactivates some members of the VEGF family, including VEGF, VEGF-B, and PlGF. Byrne et al. found that systemic administration of aflibercept prevented ascites accumulation, inhibited the growth of disseminated cancer, and resulted in dramatic remodeling of the blood vessels in an experimental model of ovarian cancer [184]. Hu et al. later showed that aflibercept plus paclitaxel strikingly reduced tumor burden and inhibited ascites while prolonging survival [202]. Aflibercept has further been investigated in some clinical studies (Table 3).

\subsection{Receptor tyrosine kinase inhibitors}

\subsubsection{VEGFR antagonists}

Agents targeting VEGF receptors have been evaluated for the use in the treatment of ovarian cancer. Ramucirumab, a fully humanized monoclonal antibody specifically blocking VEGFR-2, resulted in reduced tumor growth, increased

Table 1 Therapeutic agents targeting VEGF/VEGFR in clinical development for ovarian cancer

\begin{tabular}{|c|c|c|c|}
\hline Type & & Drug & Target(s) \\
\hline \multirow[t]{2}{*}{ VEGF binders } & & Bevacizumab & VEGF (all isoforms) \\
\hline & & Aflibercept & VEGF, VEGF-B, PlGF \\
\hline \multirow[t]{11}{*}{ Receptor tyrosine kinase inhibitors } & VEGFR inhibitors & Ramucirumab & VEGFR2 \\
\hline & & Cediranib & VEGFR1-3, c-Kit, PDGFR- $\beta$ \\
\hline & & Semaxanib & VEGFR2 \\
\hline & Multiple RTK inhibitors & Sunitinib & $\begin{array}{l}\text { VEGFR1-3, Flt-3, PDGFR- } \alpha \text {, PDGFR- } \beta \text {, } \\
\text { c-Kit, CSF-1R, RET }\end{array}$ \\
\hline & & Sorafenib & VEGFR1-3, PDGFR- $\beta$, Flt-3, c-Kit, Raf-1 \\
\hline & & Vatalanib & VEGFR1-3, PDGFR- $\beta$, c-Kit, c-Fms \\
\hline & & Intedanib & VEGFR1-3, PDGFR- $\alpha$, PDGFR- $\beta$, FGFR1-3 \\
\hline & & Pazopanib & VEGFR1-2, PDGFR- $\beta$, c-Kit \\
\hline & & Motesanib & VEGFR1-3, PDGFR, c-Kit \\
\hline & & Vandetanib & VEGFR2-3, EGFR \\
\hline & & AEE788 & VEGFR, EGFR \\
\hline
\end{tabular}

$C S F-1 R$ colony-stimulating factor 1 receptor, $E G F R$ epidermal growth factor receptor, $F G F R$ fibroblast growth factor receptor, $P D G F R$ plateletderived growth factor receptor, $P l G F$ placenta growth factor, $R T K$ receptor tyrosine kinase, $V E G F$ vascular endothelial growth factor, $V E G F R$ vascular endothelial growth factor receptor 


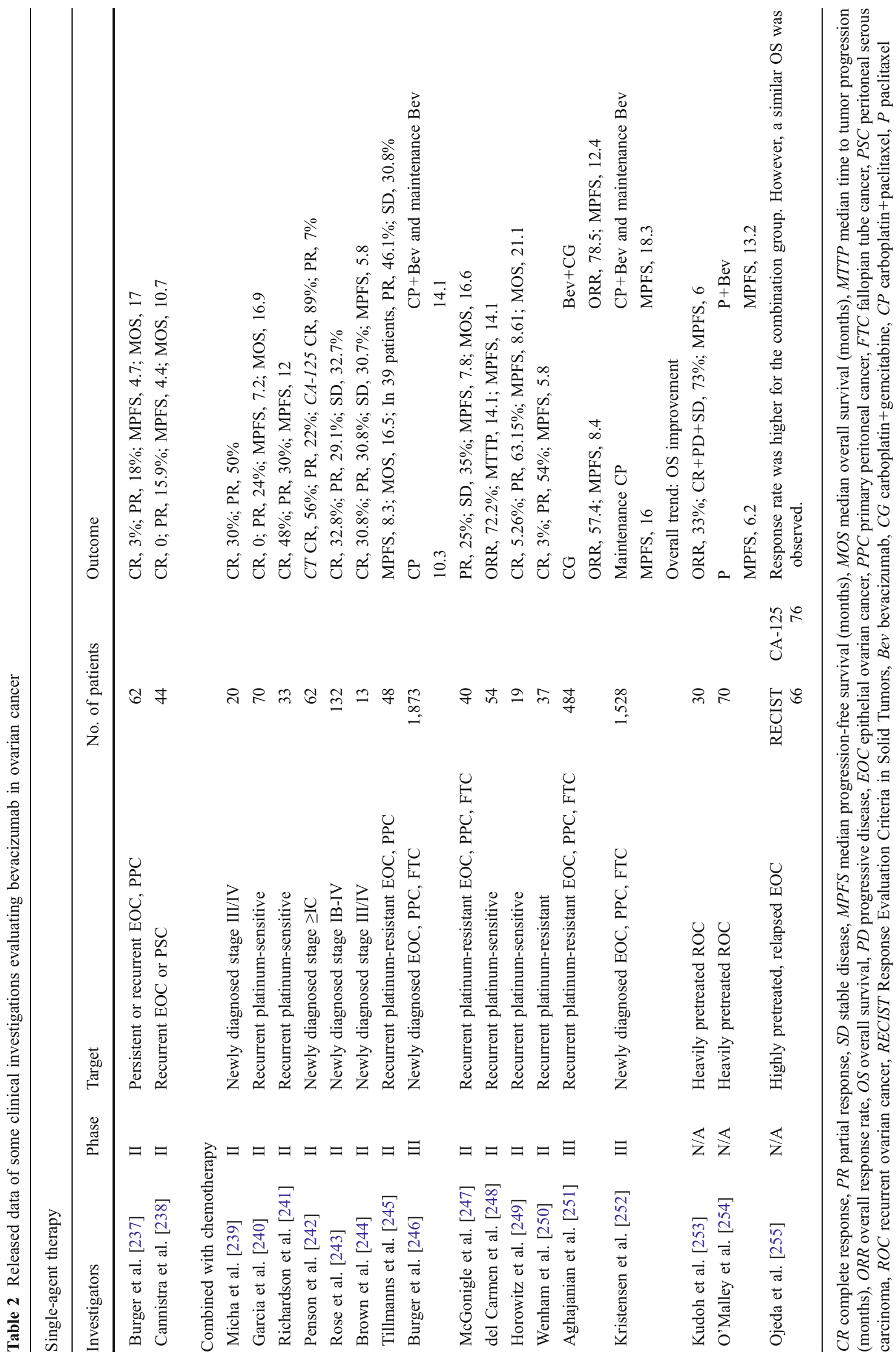


Table 3 Released data of three phase II clinical trials evaluating aflibercept (VEGF trap) in ovarian cancer

\begin{tabular}{|c|c|c|c|}
\hline Investigators & Phase & Target & Results \\
\hline Tew et al. [256] & II & $\begin{array}{l}\text { Platinum-resistant and topotecan and/or liposomal } \\
\text { doxorubicin-resistant advanced ovarian cancer }\end{array}$ & Preliminary results showed a partial response of $11 \%$. \\
\hline Colombo et al. [257] & II & $\begin{array}{l}\text { Platinum-resistant and topotecan and/or liposomal } \\
\text { doxorubicin-resistant advanced ovarian cancer with } \\
\text { recurrent symptomatic malignant ascites }\end{array}$ & $\begin{array}{l}\text { First results demonstrated the efficacy of two weekly } \\
\text { intravenous aflibercept in prolonging the time to } \\
\text { repeat paracentesis in } 8 \text { out of } 10 \text { evaluable patients. }\end{array}$ \\
\hline Coleman et al. [258] & II & Recurrent EOC, PPC, FTC & ORR, 54\%; CR, 21.7; MPFS, 6.2; MOS, 24.3 \\
\hline
\end{tabular}

$E O C$ epithelial ovarian cancer, $P P C$ primary peritoneal cancer, $F T C$ fallopian tube cancer, $V E G F$ vascular endothelial growth factor

apoptosis, and decreased tumor microvessel proliferation and density in vivo [203]. Following a phase I evaluation [204], it is currently being assessed in a phase II trial (NCT00721162) as monotherapy in patients with persistent or recurrent epithelial ovarian cancer. Cediranib, a tyrosine kinase inhibitor selectively blocking VEGFR1-3, plateletderived growth factor receptor- $\beta$ (PDGFR- $\beta$ ), and c-Kit, has been shown to inhibit the growth of human tumor xenografts, including ovarian cancer, in a dose-dependent manner [205]. Single-agent activity of cediranib in phase II trials has been reported [206, 207]. A number of the clinical studies testing cediranib in ovarian cancer are ongoing, including a three-arm randomized placebo-controlled phase III trial set to investigate cediranib in combination with platinum-based chemotherapy and as a single agent maintenance therapy in patients with platinum-sensitive relapsed ovarian cancer (ICON6). In a study by Holtz et al. [208], semaxanib reduced tumor growth and microvessel density in ovarian cancer tumors with high VEGF expression. A phase I study of semaxanib in combination with carboplatin in patients with platinum-refractory ovarian cancer (NCT00006155) has been completed (results awaited).

\subsubsection{Agents targeting multiple receptor tyrosine kinases}

As a single agent, sunitinib has demonstrated efficacy in advanced ovarian cancer in both preclinical [209] and clinical $[210,211]$ studies. Sorafenib, in a study by Matsumura et al., was shown to have an antitumor effect against ovarian clear cell carcinoma [212]. It has shown some efficacy in phase I/ II trials [213-215] and is now under further clinical investigations. In an ovarian cancer mouse model, singleagent vatalanib reduced ascites and tumor growth and yielded increased survival [191]. In a phase I study of vatalanib combined with carboplatin and paclitaxel in advanced ovarian cancer, Shroder et al. showed that vatalanib was feasible and well tolerated [216]. Monotherapy with vandetanib showed a significant antitumor effect in an ovarian cancer nude mice model [217]. However, no significant clinical benefit was made by vandetanib monotherapy in patients with recurrent ovarian cancer in a phase II clinical trial [218]. Its efficacy in combination with docetaxel in persistent or recurrent ovarian cancer will be assessed in a phase II clinical trial (NCT00872989). In a study by Hilberg et al. [219], intedanib demonstrated high activity at a welltolerated dose as decreased vessel density and vessel integrity, and profound growth inhibition in all tested tumor models. In a phase II trial, maintenance intedanib delayed disease progression in previously treated ovarian cancer patients [220]. To investigate its efficacy and safety, intedanib combined with carboplatin and paclitaxel is currently being examined in a randomized, double-blind phase III trial in patients with advanced ovarian cancer (NCT01015118). In an animal model of ovarian cancer, treatment with AEE788 plus paclitaxel significantly reduced tumor weight and increased survival of nude mice implanted with paclitaxel-sensitive cell lines compared with those treated with AEE788 alone or paclitaxel alone [221]. Also, metronomic docetaxel chemotherapy plus AEE788 was effective even in the taxane-resistant model [222]. A phase I/II randomized study of AEE788 in adult patients with advanced cancer (histologically confirmed solid tumors) has been completed (NCT00118456) and results are awaited. Pazopanib, alone or in combination with metronomic topotecan, showed anti-angiogenic and antitumor activity in a preclinical model of ovarian cancer [223]. Friedlander et al. reported pazopanib activity in a phase II trial in women with advanced epithelial ovarian cancer [224]. Other trials evaluating pazopanib efficacy as mono- or combination therapy are underway. Motesanib, that indicated antitumor activity in animal models [225], is now under clinical investigation in a phase II clinical trial (NCT00574951).

\subsection{VEGF-targeted therapy: current challenges}

Adverse effects such as hypertension, proteinuria, bowel perforation, impaired wound healing, hemorrhage, and arterial thrombotic events represent the most common toxicities associated with VEGF-targeted therapy [226, 227]. Inherent [228] and/or acquired resistance/refractoriness [226, 229] might complicate the treatment as well. Divergent effect of receptor tyrosine kinase blockade, including VEGFR inhibition, on primary tumor growth 
and metastasis leading to enhanced invasion and accelerated metastasis has been reported in preclinical studies [230, 231]. However, the clinical relevance of these findings is unclear and limited to small studies or case reports [232].

As improving overall survival while maintaining the quality of life remains the goal of all cancer treatment [233], efficacy of extended adjuvant bevacizumab in unselected populations may not be justified by the clinical benefits reported thus far [234]. Consistently, a recent analysis of GOG218 study has raised doubts about costeffectiveness of utilizing bevacizumab in the adjuvant management and maintenance therapy of patients with advanced ovarian cancer $[235,236]$. This might be in part attributed to limitations of predictive preclinical models and thus lack of appropriate preclinical testing that precedes clinical settings [232]. Besides, accurate predictors of prognosis and ideal surrogate biomarkers required for individualization of VEGF-targeted therapy are to be identified and clinically validated [227].

\section{Conclusion}

The role of VEGF in ovarian cancer growth and progression is well established. Through induction of tumor angiogenesis and vascular permeability, VEGF has a major contribution to the pathophysiology of ovarian cancer. VEGF promotes tumor growth and facilitates malignant cell invasion and dissemination. Peritoneal carcinomatosis with malignant ascites formation is the prominent pattern of ovarian cancer spread in which VEGF is significantly involved, further highlighting the crucial part played by VEGF in the progressive course of the disease. Preclinical data obtained over the last 15 years or so clearly demonstrate a central role of VEGF inhibitors in the management of ovarian cancer. On the other hand, the complexity of VEGF signaling cascade and the interacting pathways as well as the failure of preclinical studies in closely mimicking actual clinical settings represent major restrictions and barriers in translating preclinical promises to the clinic. However, this has not hindered the extensive evaluation of bevacizumab and other VEGF-targeted agents in phase II and III clinical trials, and VEGF still remains a target in the treatment of ovarian cancer.

Conflict of interest The authors declare that they have no conflict of interest.

Open Access This article is distributed under the terms of the Creative Commons Attribution Noncommercial License which permits any noncommercial use, distribution, and reproduction in any medium, provided the original author(s) and source are credited.

\section{References}

1. Chung, A. S., \& Ferrara, N. (2010). Developmental and pathological angiogenesis. Annual Review of Cell and Developmental Biology. doi:10.1146/annurev-cellbio-092910-154002.

2. Geva, E., \& Jaffe, R. B. (2000). Role of vascular endothelial growth factor in ovarian physiology and pathology. Fertility and Sterility, 74(3), 429-438.

3. Ferlay, J., Shin, H. R., Bray, F., Forman, D., Mathers, C., \& Parkin, D. M. (2010). Estimates of worldwide burden of cancer in 2008: GLOBOCAN 2008. International Journal of Cancer, 127(12), 2893-2917. doi:10.1002/ijc.25516.

4. Ramakrishnan, S., Subramanian, I. V., Yokoyama, Y., \& Geller, M. (2005). Angiogenesis in normal and neoplastic ovaries. Angiogenesis, 8(2), 169-182. doi:10.1007/s10456-005-9001-1.

5. Nakanishi, Y., Kodama, J., Yoshinouchi, M., Tokumo, K., Kamimura, S., Okuda, H., et al. (1997). The expression of vascular endothelial growth factor and transforming growth factor-beta associates with angiogenesis in epithelial ovarian cancer. International Journal of Gynecological Pathology, 16(3), 256-262.

6. Mu, J., Abe, Y., Tsutsui, T., Yamamoto, N., Tai, X.-G., Niwa, O., et al. (1996). Inhibition of growth and metastasis of ovarian carcinoma by administering a drug capable of interfering with vascular endothelial growth factor activity. Cancer Science, 87(9), 963-971.

7. Yamamoto, S., Konishi, I., Mandai, M., Kuroda, H., Komatsu, T., Nanbu, K., et al. (1997). Expression of vascular endothelial growth factor (VEGF) in epithelial ovarian neoplasms: correlation with clinicopathology and patient survival, and analysis of serum VEGF levels. British Journal of Cancer, 76(9), 1221-1227.

8. Hartenbach, E. M., Olson, T. A., Goswitz, J. J., Mohanraj, D., Twiggs, L. B., Carson, L. F., et al. (1997). Vascular endothelial growth factor (VEGF) expression and survival in human epithelial ovarian carcinomas. Cancer Letters, 121(2), 169-175.

9. Pannu, H. K., Bristow, R. E., Montz, F. J., \& Fishman, E. K. (2003). Multidetector CT of peritoneal carcinomatosis from ovarian cancer1. RadioGraphics, 23(3), 687-701. doi:10.1148/ rg. 233025105.

10. Munoz-Casares, F. C., Rufian, S., Arjona-Sanchez, A., Rubio, M. J., Diaz, R., Casado, A., et al. (2011). Neoadjuvant intraperitoneal chemotherapy with paclitaxel for the radical surgical treatment of peritoneal carcinomatosis in ovarian cancer: a prospective pilot study. Cancer Chemotherapy and Pharmacology, 68(1), 267-274. doi:10.1007/s00280-011-1646-4.

11. Meunier, L., Puiffe, M. L., Le Page, C., Filali-Mouhim, A., Chevrette, M., Tonin, P. N., et al. (2010). Effect of ovarian cancer ascites on cell migration and gene expression in an epithelial ovarian cancer in vitro model. Transl Oncol, 3(4), 230-238.

12. Roszkowski, P., Wronkowski, Z., Szamborski, J., \& Romejko, M. (1993). Evaluation of selected prognostic factors in ovarian cancer. European Journal of Gynaecological Oncology, 14 (Suppl), 140-145.

13. Zang, R. Y., Harter, P., Chi, D. S., Sehouli, J., Jiang, R., Trope, C. G., et al. (2011). Predictors of survival in patients with recurrent ovarian cancer undergoing secondary cytoreductive surgery based on the pooled analysis of an international collaborative cohort. British Journal of Cancer, 105(7), 890-896.

14. Senger, D. R., Galli, S. J., Dvorak, A. M., Perruzzi, C. A., Harvey, V. S., \& Dvorak, H. F. (1983). Tumor cells secrete a vascular permeability factor that promotes accumulation of ascites fluid. Science, 219(4587), 983-985.

15. Ferrara, N., \& Henzel, W. J. (1989). Pituitary follicular cells secrete a novel heparin-binding growth factor specific for vascular endothelial cells. Biochemical and Biophysical Research Communications, 161(2), 851-858. 
16. Connolly, D. T., Olander, J. V., Heuvelman, D., Nelson, R., Monsell, R., Siegel, N., et al. (1989). Human vascular permeability factor. Isolation from U937 cells. Journal of Biological Chemistry, 26(33), 20017-20024.

17. Keck, P. J., Hauser, S. D., Krivi, G., Sanzo, K., Warren, T., Feder, J., et al. (1989). Vascular permeability factor, an endothelial cell mitogen related to PDGF. Science, 246(4935), 1309-1312.

18. Leung, D. W., Cachianes, G., Kuang, W. J., Goeddel, D. V., \& Ferrara, N. (1989). Vascular endothelial growth factor is a secreted angiogenic mitogen. Science, 246(4935), 1306-1309.

19. Yamazaki, Y., \& Morita, T. (2006). Molecular and functional diversity of vascular endothelial growth factors. Molecular Diversity, 10(4), 515-527. doi:10.1007/s11030-006-9027-3.

20. Woolard, J., Bevan, H. S., Harper, S. J., \& Bates, D. O. (2009). Molecular diversity of VEGF-A as a regulator of its biological activity. Microcirculation, 16(7), 572-592. doi:10.1080/ 10739680902997333.

21. Kowanetz, M., \& Ferrara, N. (2006). Vascular endothelial growth factor signaling pathways: therapeutic perspective. Clinical Cancer Research, 12(17), 5018-5022. doi:10.1158/ 1078-0432.ccr-06-1520.

22. Crawford, Y., \& Ferrara, N. (2009). VEGF inhibition: insights from preclinical and clinical studies. Cell and Tissue Research, 335(1), 261-269. doi:10.1007/s00441-008-0675-8.

23. Ferrara, N. (2010). Binding to the extracellular matrix and proteolytic processing: two key mechanisms regulating vascular endothelial growth factor action. Molecular Biology of the Cell, 21(5), 687-690. doi:10.1091/mbc.E09-07-0590.

24. Olsson, A. K., Dimberg, A., Kreuger, J., \& Claesson-Welsh, L. (2006). VEGF receptor signalling-in control of vascular function. Nature Reviews Molecular Cell Biology, 7(5), 359371. doi:10.1038/nrm1911.

25. Robinson, C. J., \& Stringer, S. E. (2001). The splice variants of vascular endothelial growth factor (VEGF) and their receptors. Journal of Cell Science, 114(Pt 5), 853-865.

26. Jakeman, L. B., Winer, J., Bennett, G. L., Altar, C. A., \& Ferrara, N. (1992). Binding sites for vascular endothelial growth factor are localized on endothelial cells in adult rat tissues. The Journal of Clinical Investigation, 89(1), 244-253. doi:10.1172/jci115568.

27. Jakeman, L. B., Armanini, M., Phillips, H. S., \& Ferrara, N. (1993). Developmental expression of binding sites and messenger ribonucleic acid for vascular endothelial growth factor suggests a role for this protein in vasculogenesis and angiogenesis. Endocrinology, 133(2), 848-859.

28. Shen, H., Clauss, M., Ryan, J., Schmidt, A. M., Tijburg, P., Borden, L., et al. (1993). Characterization of vascular permeability factor/vascular endothelial growth factor receptors on mononuclear phagocytes. Blood, 81(10), 2767-2773.

29. Cross, M. J., Dixelius, J., Matsumoto, T., \& Claesson-Welsh, L. (2003). VEGF-receptor signal transduction. Trends in Biochemical Sciences, 28(9), 488-494

30. Ferrara, N., Gerber, H. P., \& LeCouter, J. (2003). The biology of VEGF and its receptors. Nature Medicine, 9(6), 669-676. doi:10.1038/nm0603-669.

31. Makinen, T., Veikkola, T., Mustjoki, S., Karpanen, T., Catimel, B., Nice, E. C., et al. (2001). Isolated lymphatic endothelial cells transduce growth, survival and migratory signals via the VEGFC/D receptor VEGFR-3. EMBO Journal, 20(17), 4762-4773. doi:10.1093/emboj/20.17.4762.

32. Gerber, H. P., McMurtrey, A., Kowalski, J., Yan, M., Keyt, B. A., Dixit, V., et al. (1998). Vascular endothelial growth factor regulates endothelial cell survival through the phosphatidylinositol 3'-kinase/Akt signal transduction pathway. Requirement for Flk-1/ KDR activation. Journal of Biological Chemistry, 273(46), 30336-30343.
33. Gerber, H. P., Dixit, V., \& Ferrara, N. (1998). Vascular endothelial growth factor induces expression of the antiapoptotic proteins Bcl-2 and A1 in vascular endothelial cells. Journal of Biological Chemistry, 273(21), 13313-13316.

34. Tran, J., Rak, J., Sheehan, C., Saibil, S. D., LaCasse, E., Korneluk, R. G., et al. (1999). Marked induction of the IAP family antiapoptotic proteins survivin and XIAP by VEGF in vascular endothelial cells. Biochemical and Biophysical Research Communications, 264(3), 781-788. doi:10.1006/ bbrc.1999.1589.

35. Chung, A. S., Lee, J., \& Ferrara, N. (2010). Targeting the tumour vasculature: insights from physiological angiogenesis. Nature Reviews. Cancer, 10(7), 505-514. doi:10.1038/nrc2868.

36. Bates, D. O., \& Harper, S. J. (2002). Regulation of vascular permeability by vascular endothelial growth factors. Vascular Pharmacology, 39(4-5), 225-237.

37. Issbrucker, K., Marti, H. H., Hippenstiel, S., Springmann, G., Voswinckel, R., Gaumann, A., et al. (2003). p38 MAP kinase-a molecular switch between VEGF-induced angiogenesis and vascular hyperpermeability. The FASEB Journal, 17(2), 262264. doi:10.1096/fj.02-0329fje.

38. Kroll, J., \& Waltenberger, J. (1999). A novel function of VEGF receptor-2 (KDR): rapid release of nitric oxide in response to VEGF-A stimulation in endothelial cells. Biochemical and Biophysical Research Communications, 265(3), 636-639. doi:10.1006/bbrc.1999.1729.

39. Yla-Herttuala, S., Rissanen, T. T., Vajanto, I., \& Hartikainen, J. (2007). Vascular endothelial growth factors: biology and current status of clinical applications in cardiovascular medicine. Journal of the American College of Cardiology, 49(10), 10151026. doi:10.1016/j.jacc.2006.09.053

40. Ferrara, N. (2001). Role of vascular endothelial growth factor in regulation of physiological angiogenesis. American Journal of Physiology. Cell Physiology, 280(6), C1358-C1366.

41. Brown, L. F., Yeo, K. T., Berse, B., Yeo, T. K., Senger, D. R., Dvorak, H. F., et al. (1992). Expression of vascular permeability factor (vascular endothelial growth factor) by epidermal keratinocytes during wound healing. The Journal of Experimental Medicine, 176(5), 1375-1379.

42. Kumar, I., Staton, C. A., Cross, S. S., Reed, M. W., \& Brown, N. J. (2009). Angiogenesis, vascular endothelial growth factor and its receptors in human surgical wounds. British Journal of Surgery, 96(12), 1484-1491. doi:10.1002/bjs.6778.

43. Westenbrink, B. D., Ruifrok, W. P., Voors, A. A., Tilton, R. G., van Veldhuisen, D. J., Schoemaker, R. G., et al. (2010). Vascular endothelial growth factor is crucial for erythropoietin-induced improvement of cardiac function in heart failure. Cardiovascular Research, 87(1), 30-39. doi:10.1093/cvr/cvq041.

44. Lee, C., \& Agoston, D. V. (2010). Vascular endothelial growth factor is involved in mediating increased de novo hippocampal neurogenesis in response to traumatic brain injury. Journal of Neurotrauma, 27(3), 541-553. doi:10.1089/neu.2009.0905.

45. Olfert, I. M., Howlett, R. A., Wagner, P. D., \& Breen, E. C. (2010). Myocyte vascular endothelial growth factor is required for exerciseinduced skeletal muscle angiogenesis. American Journal of Physiology - Regulatory, Integrative and Comparative Physiology, 299(4), R1059-R1067. doi:10.1152/ajpregu.00347.2010.

46. Taylor, P. D., Wilson, H., Hillier, S. G., Wiegand, S. J., \& Fraser, H. M. (2007). Effects of inhibition of vascular endothelial growth factor at time of selection on follicular angiogenesis, expansion, development and atresia in the marmoset. Molecular Human Reproduction, 13(10), 729-736. doi:10.1093/molehr/ gam056.

47. Kumaran, G. C., Jayson, G. C., \& Clamp, A. R. (2009). Antiangiogenic drugs in ovarian cancer. British Journal of Cancer, 100(1), 1-7. doi:10.1038/sj.bjc.6604767. 
48. Zimmermann, R. C., Xiao, E., Husami, N., Sauer, M. V., Lobo, R., Kitajewski, J., et al. (2001). Short-term administration of antivascular endothelial growth factor antibody in the late follicular phase delays follicular development in the rhesus monkey. Journal of Clinical Endocrinology and Metabolism, 86 (2), 768-772.

49. Wulff, C., Wiegand, S. J., Saunders, P. T., Scobie, G. A., \& Fraser, H. M. (2001). Angiogenesis during follicular development in the primate and its inhibition by treatment with truncated Flt-1-Fc (vascular endothelial growth factor Trap(A40)). Endocrinology, 142(7), 3244-3254.

50. Zimmermann, R. C., Xiao, E., Bohlen, P., \& Ferin, M. (2002). Administration of antivascular endothelial growth factor receptor 2 antibody in the early follicular phase delays follicular selection and development in the rhesus monkey. Endocrinology, 143(7), 2496-2502.

51. Zimmermann, R. C., Hartman, T., Kavic, S., Pauli, S. A., Bohlen, P., Sauer, M. V., et al. (2003). Vascular endothelial growth factor receptor 2-mediated angiogenesis is essential for gonadotropindependent follicle development. The Journal of Clinical Investigation, 112(5), 659-669. doi:10.1172/jci18740.

52. Fraser, H. M., Wilson, H., Rudge, J. S., \& Wiegand, S. J. (2005). Single injections of vascular endothelial growth factor trap block ovulation in the macaque and produce a prolonged, dose-related suppression of ovarian function. Journal of Clinical Endocrinology and Metabolism, 90(2), 1114-1122. doi:10.1210/jc.2004-1572.

53. Koos, R. D. (1995). Increased expression of vascular endothelial growth/permeability factor in the rat ovary following an ovulatory gonadotropin stimulus: potential roles in follicle rupture. Biology of Reproduction, 52(6), 1426-1435.

54. Ferrara, N., Chen, H., Davis-Smyth, T., Gerber, H. P., Nguyen, T. N., Peers, D., et al. (1998). Vascular endothelial growth factor is essential for corpus luteum angiogenesis. Nature Medicine, 4(3), 336-340.

55. Fraser, H. M., \& Wulff, C. (2003). Angiogenesis in the corpus luteum. Reproductive Biology and Endocrinology, 1, 88. doi:10.1186/1477-7827-1-88.

56. Doyle, L. K., Walker, C. A., \& Donadeu, F. X. (2010). VEGF modulates the effects of gonadotropins in granulosa cells. Domestic Animal Endocrinology, 38(3), 127-137. doi:10.1016/ j.domaniend.2009.08.008.

57. Greenaway, J., Connor, K., Pedersen, H. G., Coomber, B. L., LaMarre, J., \& Petrik, J. (2004). Vascular endothelial growth factor and its receptor, Flk-1/KDR, are cytoprotective in the extravascular compartment of the ovarian follicle. Endocrinology, 145(6), 2896-2905. doi:10.1210/en.2003-1620.

58. Grasselli, F., Basini, G., Bussolati, S., \& Tamanini, C. (2002). Effects of VEGF and bFGF on proliferation and production of steroids and nitric oxide in porcine granulosa cells. Reproduction in Domestic Animals, 37(6), 362-368. doi:10.1046/j.14390531.2002.00386.x

59. Rolaki, A., Coukos, G., Loutradis, D., DeLisser, H. M., Coutifaris, C., \& Makrigiannakis, A. (2007). Luteogenic hormones act through a vascular endothelial growth factordependent mechanism to up-regulate $\alpha 5 \beta 1$ and $\alpha \mathrm{v} \beta 3$ integrins, promoting the migration and survival of human luteinized granulosa cells. American Journal of Pathology, 170(5), 15611572. doi:10.2353/ajpath.2007.060926.

60. Scott, A., Powner, M. B., Gandhi, P., Clarkin, C., Gutmann, D. H., Johnson, R. S., et al. (2010). Astrocyte-derived vascular endothelial growth factor stabilizes vessels in the developing retinal vasculature. PloS One, 5(7), e11863. doi:10.1371/journal. pone. 0011863 .

61. Smith, L. E. (2008). Through the eyes of a child: understanding retinopathy through ROP the Friedenwald lecture. Investigative Ophthalmology \& Visual Science, 49(12), 5177-5182. doi:10.1167/iovs.08-2584.
62. Mahdy, R. A., Nada, W. M., Hadhoud, K. M., \& El-Tarhony, S. A. (2010). The role of vascular endothelial growth factor in the progression of diabetic vascular complications. Eye (London, England), 24(10), 1576-1584. doi:10.1038/eye.2010.86.

63. Yasuda, S., Kachi, S., Kondo, M., Ushida, H., Uetani, R., Terui, T., et al. (2011). Significant correlation between electroretinogram parameters and ocular vascular endothelial growth factor concentration in central retinal vein occlusion eyes. Investigative Ophthalmology \& Visual Science, 52(8), 5737-5742. doi:10.1167/iovs.10-6923.

64. Ferrara, N. (2010). Vascular endothelial growth factor and age-related macular degeneration: from basic science to therapy. Nature Medicine, 16(10), 1107-1111. doi:10.1038/ nm1010-1107.

65. Canavese, M., Altruda, F., Ruzicka, T., \& Schauber, J. (2010). Vascular endothelial growth factor (VEGF) in the pathogenesis of psoriasis - a possible target for novel therapies? Journal of Dermatological Science, 58(3), 171-176. doi:10.1016/j. jdermsci.2010.03.023.

66. Kurosaka, D., Hirai, K., Nishioka, M., Miyamoto, Y., Yoshida, K., Noda, K., et al. (2010). Clinical significance of serum levels of vascular endothelial growth factor, angiopoietin-1, and angiopoietin-2 in patients with rheumatoid arthritis. Journal of Rheumatology, 37(6), 1121-1128. doi:10.3899/jrheum.090941.

67. Murata, M., Yudoh, K., \& Masuko, K. (2008). The potential role of vascular endothelial growth factor (VEGF) in cartilage: how the angiogenic factor could be involved in the pathogenesis of osteoarthritis? Osteoarthritis and Cartilage, 16(3), 279-286. doi:10.1016/j.joca.2007.09.003.

68. Otto, K., Duchrow, M., Broll, R., Bruch, H. P., \& Strik, M. W. (2002). Expression of vascular endothelial growth factor mRNA and protein in human chronic renal allograft rejection. Transplantation Proceedings, 34(8), 3134-3137.

69. Reinders, M. E., Fang, J. C., Wong, W., Ganz, P., \& Briscoe, D. M. (2003). Expression patterns of vascular endothelial growth factor in human cardiac allografts: association with rejection. Transplantation, 76(1), 224-230. doi:10.1097/01.tp.0000071363.55007.d0.

70. Nag, S., Kapadia, A., \& Stewart, D. J. (2011). Review: molecular pathogenesis of blood-brain barrier breakdown in acute brain injury. Neuropathology and Applied Neurobiology, 37(1), 3-23. doi:10.1111/j.1365-2990.2010.01138.x.

71. Przewratil, P., Sitkiewicz, A., \& Andrzejewska, E. (2010). Local serum levels of vascular endothelial growth factor in infantile hemangioma: intriguing mechanism of endothelial growth. Cytokine, 49(2), 141-147. doi:10.1016/j.cyto.2009.11.012.

72. Celletti, F. L., Waugh, J. M., Amabile, P. G., Brendolan, A., Hilfiker, P. R., \& Dake, M. D. (2001). Vascular endothelial growth factor enhances atherosclerotic plaque progression. Nature Medicine, 7(4), 425-429. doi:10.1038/86490.

73. Nordlie, M. A., Wold, L. E., Simkhovich, B. Z., Sesti, C., \& Kloner, R. A. (2006). Molecular aspects of ischemic heart disease: ischemia/reperfusion-induced genetic changes and potential applications of gene and RNA interference therapy. Journal of Cardiovascular Pharmacology and Therapeutics, 11 (1), 17-30.

74. Stehr, A., Topel, I., Muller, S., Unverdorben, K., Geissler, E. K., Kasprzak, P. M., et al. (2010). VEGF: a surrogate marker for peripheral vascular disease. European Journal of Vascular and Endovascular Surgery, 39(3), 330-332. doi:10.1016/j. ejvs.2009.09.025.

75. Chi, O. Z., Hunter, C., Liu, X., \& Weiss, H. R. (2007). Effects of anti-VEGF antibody on blood-brain barrier disruption in focal cerebral ischemia. Experimental Neurology, 204(1), 283-287. doi:10.1016/j.expneurol.2006.11.001.

76. Peitsidis, P., \& Agrawal, R. (2010). Role of vascular endothelial growth factor in women with PCO and PCOS: a systematic 
review. Reproductive Biomedicine Online, 20(4), 444-452. doi:10.1016/j.rbmo.2010.01.007.

77. Ren, Q. Z., Qian, Z. H., Jia, S. H., \& Xu, Z. Z. (2011). Vascular endothelial growth factor expression up-regulated by endometrial ischemia in secretory phase plays an important role in endometriosis. Fertility and Sterility, 95(8), 2687-2689. doi:10.1016/j. fertnstert.2011.05.001.

78. Murakami, Y., Kobayashi, T., Omatsu, K., Suzuki, M., Ohashi, R., Matsuura, T., et al. (2005). Exogenous vascular endothelial growth factor can induce preeclampsia-like symptoms in pregnant mice. Seminars in Thrombosis and Hemostasis, 31(3), 307-313. doi:10.1055/s-2005-872437.

79. Bussen, S., \& Bussen, D. (2011). Influence of the vascular endothelial growth factor on the development of severe preeclampsia or HELLP syndrome. Archives of Gynecology and Obstetrics, 284(3), 551-557. doi:10.1007/s00404-010-1704-x.

80. Carmeliet, P. (2005). Angiogenesis in life, disease and medicine. Nature, 438(7070), 932-936. doi:10.1038/nature04478.

81. Volm, M., Koomagi, R., Mattern, J., \& Stammler, G. (1997). Angiogenic growth factors and their receptors in non-small cell lung carcinomas and their relationships to drug response in vitro. Anticancer Research, 17(1A), 99-103.

82. Brown, L. F., Berse, B., Jackman, R. W., Tognazzi, K., Guidi, A. J., Dvorak, H. F., et al. (1995). Expression of vascular permeability factor (vascular endothelial growth factor) and its receptors in breast cancer. Human Pathology, 26(1), 86-91.

83. Brown, L. F., Berse, B., Jackman, R. W., Tognazzi, K., Manseau, E. J., Senger, D. R., et al. (1993). Expression of vascular permeability factor (vascular endothelial growth factor) and its receptors in adenocarcinomas of the gastrointestinal tract. Cancer Research, 53(19), 4727-4735.

84. Brown, L. F., Berse, B., Jackman, R. W., Tognazzi, K., Manseau, E. J., Dvorak, H. F., et al. (1993). Increased expression of vascular permeability factor (vascular endothelial growth factor) and its receptors in kidney and bladder carcinomas. American Journal of Pathology, 143(5), 1255-1262.

85. Guidi, A. J., Abu-Jawdeh, G., Tognazzi, K., Dvorak, H. F., \& Brown, L. F. (1996). Expression of vascular permeability factor (vascular endothelial growth factor) and its receptors in endometrial carcinoma. Cancer, 78(3), 454-460. doi:10.1002/(sici)1097-0142 (19960801)78:3<454::aid-cncr12>3.0.co;2-y.

86. Huang, H., Held-Feindt, J., Buhl, R., Mehdorn, H. M., \& Mentlein, R. (2005). Expression of VEGF and its receptors in different brain tumors. Neurological Research, 27(4), 371-377. doi:10.1179/016164105x39833.

87. Turner, H. E., Harris, A. L., Melmed, S., \& Wass, J. A. (2003). Angiogenesis in endocrine tumors. Endocrine Reviews, 24(5), 600-632.

88. Fukumura, D., Xavier, R., Sugiura, T., Chen, Y., Park, E. C., Lu, N., et al. (1998). Tumor induction of VEGF promoter activity in stromal cells. Cell, 94(6), 715-725.

89. Gerber, H. P., Kowalski, J., Sherman, D., Eberhard, D. A., \& Ferrara, N. (2000). Complete inhibition of rhabdomyosarcoma xenograft growth and neovascularization requires blockade of both tumor and host vascular endothelial growth factor. Cancer Research, 60(22), 6253-6258.

90. Folkman, J. (1971). Tumor angiogenesis: therapeutic implications. The New England Journal of Medicine, 285(21), 11821186. doi:10.1056/nejm197111182852108.

91. Carmeliet, P. (2005). VEGF as a key mediator of angiogenesis in cancer. Oncology, 69(Suppl 3), 4-10. doi:10.1159/000088478.

92. Kamba, T., Tam, B. Y., Hashizume, H., Haskell, A., Sennino, B., Mancuso, M. R., et al. (2006). VEGF-dependent plasticity of fenestrated capillaries in the normal adult microvasculature. American Journal of Physiology - Heart and Circulatory Physiology, 290(2), H560-H576. doi:10.1152/ajpheart.00133.2005.
93. Nor, J. E., Christensen, J., Liu, J., Peters, M., Mooney, D. J., Strieter, R. M., et al. (2001). Up-regulation of Bcl-2 in microvascular endothelial cells enhances intratumoral angiogenesis and accelerates tumor growth. Cancer Research, 61(5), 2183-2188.

94. Folkman, J. (2003). Angiogenesis and apoptosis. Seminars in Cancer Biology, 13(2), 159-167.

95. Dvorak, H. F., Brown, L. F., Detmar, M., \& Dvorak, A. M. (1995). Vascular permeability factor/vascular endothelial growth factor, microvascular hyperpermeability, and angiogenesis. American Journal of Pathology, 146(5), 1029-1039.

96. Unemori, E. N., Ferrara, N., Bauer, E. A., \& Amento, E. P. (1992). Vascular endothelial growth factor induces interstitial collagenase expression in human endothelial cells. Journal of Cellular Physiology, 153(3), 557-562. doi:10.1002/ jcp.1041530317.

97. Bamberger, E. S., \& Perrett, C. W. (2002). Angiogenesis in epithelian ovarian cancer. Molecular Pathology, 55(6), 348-359.

98. Lichtenberger, B. M., Tan, P. K., Niederleithner, H., Ferrara, N., Petzelbauer, P., \& Sibilia, M. (2010). Autocrine VEGF signaling synergizes with EGFR in tumor cells to promote epithelial cancer development. Cell, 140(2), 268-279. doi:10.1016/j. cell.2009.12.046.

99. Mercurio, A. M., Bachelder, R. E., Bates, R. C., \& Chung, J. (2004). Autocrine signaling in carcinoma: VEGF and the alpha6beta4 integrin. Seminars in Cancer Biology, 14(2), 115122. doi:10.1016/j.semcancer.2003.09.016.

100. Gabrilovich, D. I., Chen, H. L., Girgis, K. R., Cunningham, H. T., Meny, G. M., Nadaf, S., et al. (1996). Production of vascular endothelial growth factor by human tumors inhibits the functional maturation of dendritic cells. Nature Medicine, 2(10), 1096-1103.

101. Oyama, T., Ran, S., Ishida, T., Nadaf, S., Kerr, L., Carbone, D. P., et al. (1998). Vascular endothelial growth factor affects dendritic cell maturation through the inhibition of nuclear factorkappa B activation in hemopoietic progenitor cells. Journal of Immunology, 160(3), 1224-1232.

102. Kaplan, R. N., Riba, R. D., Zacharoulis, S., Bramley, A. H., Vincent, L., Costa, C., et al. (2005). VEGFR1-positive haematopoietic bone marrow progenitors initiate the pre-metastatic niche. Nature, 438(7069), 820-827. doi:10.1038/nature04186.

103. Gerber, H. P., \& Ferrara, N. (2003). The role of VEGF in normal and neoplastic hematopoiesis. Journal Molecule Medicine (Berl), 81(1), 20-31. doi:10.1007/s00109-002-0397-4.

104. Medinger, M., Fischer, N., \& Tzankov, A. (2010). Vascular endothelial growth factor-related pathways in hemato-lymphoid malignancies. Journal Oncology, 2010, 729725. doi:10.1155/ 2010/729725.

105. Olson, T. A., Mohanraj, D., Carson, L. F., \& Ramakrishnan, S. (1994). Vascular permeability factor gene expression in normal and neoplastic human ovaries. Cancer Research, 54(1), 276-280.

106. Abu-Jawdeh, G. M., Faix, J. D., Niloff, J., Tognazzi, K., Manseau, E., Dvorak, H. F., et al. (1996). Strong expression of vascular permeability factor (vascular endothelial growth factor) and its receptors in ovarian borderline and malignant neoplasms. Laboratory Investigation, 74(6), 1105-1115.

107. Hazelton, D., Nicosia, R. F., \& Nicosia, S. V. (1999). Vascular endothelial growth factor levels in ovarian cyst fluid correlate with malignancy. Clinical Cancer Research, 5(4), 823-829.

108. Schumacher, J. J., Dings, R. P., Cosin, J., Subramanian, I. V., Auersperg, N., \& Ramakrishnan, S. (2007). Modulation of angiogenic phenotype alters tumorigenicity in rat ovarian epithelial cells. Cancer Research, 67(8), 3683-3690. doi:10.1158/0008-5472.can-06-3608.

109. Santin, A. D., Hermonat, P. L., Ravaggi, A., Cannon, M. J., Pecorelli, S., \& Parham, G. P. (1999). Secretion of vascular 
endothelial growth factor in ovarian cancer. European Journal of Gynaecological Oncology, 20(3), 177-181.

110. Paley, P. J., Staskus, K. A., Gebhard, K., Mohanraj, D., Twiggs, L. B., Carson, L. F., et al. (1997). Vascular endothelial growth factor expression in early stage ovarian carcinoma. Cancer, 80 (1), 98-106.

111. Kassim, S. K., El-Salahy, E. M., Fayed, S. T., Helal, S. A., Helal, T., Azzam Eel, D., et al. (2004). Vascular endothelial growth factor and interleukin-8 are associated with poor prognosis in epithelial ovarian cancer patients. Clinical Biochemistry, 37(5), 363-369. doi:10.1016/j.clinbiochem.2004.01.014.

112. Chambers, S. K., Clouser, M. C., Baker, A. F., Roe, D. J., Cui, H., Brewer, M. A., et al. (2010). Overexpression of tumor vascular endothelial growth factor A may portend an increased likelihood of progression in a phase II trial of bevacizumab and erlotinib in resistant ovarian cancer. Clinical Cancer Research, 16(21), 5320-5328. doi:10.1158/1078-0432.ccr-10-0974.

113. Siddiqui, G. K., Elmasry, K., Wong Te Fong, A. C., Perrett, C., Morris, R., Crow, J. C., et al. (2010). Prognostic significance of intratumoral vascular endothelial growth factor as a marker of tumour angiogenesis in epithelial ovarian cancer. European Journal of Gynaecological Oncology, 31(2), 156-159.

114. Siddiqui, G. K., Wong Te Fong, L. F., Rolfe, K. J., Hadjat, S., Reid, W. M. N., Maclean, A. B., et al. (2001). Abstracts presented at the Scientific Meeting, Portsmouth, 10th and 11th November 2000. BJOG: An International Journal of Obstetrics and Gynaecology, 108(5), 547-557. doi:10.1111/j.1471-0528.2001.00126.x.

115. Zebrowski, B. K., Liu, W., Ramirez, K., Akagi, Y., Mills, G. B., \& Ellis, L. M. (1999). Markedly elevated levels of vascular endothelial growth factor in malignant ascites. Annals of Surgical Oncology, 6(4), 373-378.

116. Bamias, A., Koutsoukou, V., Terpos, E., Tsiatas, M. L., Liakos, C., Tsitsilonis, O., et al. (2008). Correlation of NK T-like CD3+CD56+ cells and CD4+CD25+(hi) regulatory $\mathrm{T}$ cells with VEGF and TNFalpha in ascites from advanced ovarian cancer: association with platinum resistance and prognosis in patients receiving first-line, platinum-based chemotherapy. Gynecologic Oncology, 108(2), 421-427. doi:10.1016/j.ygyno.2007.10.018.

117. Cooper, B. C., Ritchie, J. M., Broghammer, C. L., Coffin, J., Sorosky, J. I., Buller, R. E., et al. (2002). Preoperative serum vascular endothelial growth factor levels: significance in ovarian cancer. Clinical Cancer Research, 8(10), 3193-3197.

118. Li, L., Wang, L., Zhang, W., Tang, B., Zhang, J., Song, H., et al. (2004). Correlation of serum VEGF levels with clinical stage, therapy efficacy, tumor metastasis and patient survival in ovarian cancer. Anticancer Research, 24(3b), 1973-1979.

119. Hefler, L. A., Zeillinger, R., Grimm, C., Sood, A. K., Cheng, W. F., Gadducci, A., et al. (2006). Preoperative serum vascular endothelial growth factor as a prognostic parameter in ovarian cancer. Gynecologic Oncology, 103(2), 512-517. doi:10.1016/j. ygyno.2006.03.058.

120. Ferrara, N., \& Kerbel, R. S. (2005). Angiogenesis as a therapeutic target. Nature, 438(7070), 967-974. doi:10.1038/ nature 04483 .

121. Osada, R., Horiuchi, A., Kikuchi, N., Ohira, S., Ota, M., Katsuyama, Y., et al. (2006). Expression of semaphorins, vascular endothelial growth factor, and their common receptor neuropilins and alleic loss of semaphorin locus in epithelial ovarian neoplasms: increased ratio of vascular endothelial growth factor to semaphorin is a poor prognostic factor in ovarian carcinomas. Human Pathology, 37(11), 1414-1425. doi:10.1016/j.humpath.2006.04.031.

122. Hefler, L. A., Mustea, A., Konsgen, D., Concin, N., Tanner, B., Strick, R., et al. (2007). Vascular endothelial growth factor gene polymorphisms are associated with prognosis in ovarian cancer.
Clinical Cancer Research, 13(3), 898-901. doi:10.1158/10780432.ccr-06-1008.

123. Horiuchi, A., Imai, T., Shimizu, M., Oka, K., Wang, C., Nikaido, T., et al. (2002). Hypoxia-induced changes in the expression of VEGF, HIF-1 alpha and cell cycle-related molecules in ovarian cancer cells. Anticancer Research, 22(5), 2697-2702.

124. Skinner, H. D., Zheng, J. Z., Fang, J., Agani, F., \& Jiang, B.-H. (2004). Vascular endothelial growth factor transcriptional activation is mediated by hypoxia-inducible factor $1 \alpha$, HDM2, and p70S6K1 in response to phosphatidylinositol 3-kinase/AKT signaling. Journal of Biological Chemistry, 279(44), 4564345651. doi:10.1074/jbc.M404097200.

125. Kryczek, I., Lange, A., Mottram, P., Alvarez, X., Cheng, P., Hogan, M., et al. (2005). CXCL12 and vascular endothelial growth factor synergistically induce neoangiogenesis in human ovarian cancers. Cancer Research, 65(2), 465-472.

126. Cao, Z., Fang, J., Xia, C., Shi, X., \& Jiang, B.-H. (2004). trans$3,4,5^{\prime}$-Trihydroxystibene inhibits hypoxia-inducible factor $1 \alpha$ and vascular endothelial growth factor expression in human ovarian cancer cells. Clinical Cancer Research, 10(15), 5253 5263. doi:10.1158/1078-0432.ccr-03-0588.

127. Liu, L.-Z., Hu, X.-W., Xia, C., He, J., Zhou, Q., Shi, X., et al. (2006). Reactive oxygen species regulate epidermal growth factorinduced vascular endothelial growth factor and hypoxia-inducible factor- $1 \alpha$ expression through activation of AKT and P70S6K1 in human ovarian cancer cells. Free Radical Biology \& Medicine, 41 (10), 1521-1533. doi:10.1016/j.freeradbiomed.2006.08.003.

128. Matei, D., Kelich, S., Cao, L., Menning, N., Emerson, R. E., Rao, J., et al. (2007). PDGF BB induces VEGF secretion in ovarian cancer. Cancer Biology \& Therapy, 6(12), 1951-1959.

129. Liao, S., Liu, J., Lin, P., Shi, T., Jain, R. K., \& Xu, L. (2011). TGFbeta blockade controls ascites by preventing abnormalization of lymphatic vessels in orthotopic human ovarian carcinoma models. Clinical Cancer Research, 17(6), 1415-1424. doi:10.1158/10780432.ccr-10-2429.

130. Kulbe, H., Thompson, R., Wilson, J. L., Robinson, S., Hagemann, T., Fatah, R., et al. (2007). The inflammatory cytokine tumor necrosis factor-alpha generates an autocrine tumor-promoting network in epithelial ovarian cancer cells. Cancer Research, 67(2), 585-592. doi:10.1158/0008-5472. can-06-2941.

131. Dai, L., Gu, L., Ding, C., Qiu, L., \& Di, W. (2009). TWEAK promotes ovarian cancer cell metastasis via NF-kappaB pathway activation and VEGF expression. Cancer Letters, 283(2), 159167. doi:10.1016/j.canlet.2009.03.036.

132. Stadlmann, S., Amberger, A., Pollheimer, J., Gastl, G., Offner, F. A., Margreiter, R., et al. (2005). Ovarian carcinoma cells and IL1beta-activated human peritoneal mesothelial cells are possible sources of vascular endothelial growth factor in inflammatory and malignant peritoneal effusions. Gynecologic Oncology, 97 (3), 784-789. doi:10.1016/j.ygyno.2005.02.017.

133. Coward, J., Kulbe, H., Chakravarty, P., Leader, D. A., Vassileva, V., Leinster, D. A., et al. (2011). Interleukin-6 as a therapeutic target in human ovarian cancer. Clinical Cancer Research. doi:10.1158/1078-0432.ccr-11-0945.

134. Salani, D., Di Castro, V., Nicotra, M. R., Rosano, L., Tecce, R., Venuti, A., et al. (2000). Role of endothelin-1 in neovascularization of ovarian carcinoma. American Journal of Pathology, 157 (5), 1537-1547. doi:10.1016/s0002-9440(10)64791-8.

135. Kandalaft, L. E., Motz, G. T., Duraiswamy, J., \& Coukos, G. (2011). Tumor immune surveillance and ovarian cancer: lessons on immune mediated tumor rejection or tolerance. Cancer and Metastasis Reviews, 30(1), 141-151.

136. Yokoyama, Y., Xin, B., Shigeto, T., \& Mizunuma, H. (2011). Combination of ciglitazone, a peroxisome proliferator-activated receptor gamma ligand, and cisplatin enhances the inhibition of 
growth of human ovarian cancers. Journal of Cancer Research and Clinical Oncology, 137(8), 1219-1228. doi:10.1007/s00432011-0993-1.

137. Schiffenbauer, Y. S., Abramovitch, R., Meir, G., Nevo, N., Holzinger, M., Itin, A., et al. (1997). Loss of ovarian function promotes angiogenesis in human ovarian carcinoma. Proceedings of the National Academy of Sciences of the United States of America, 94(24), 13203-13208.

138. Wang, J., Luo, F., Lu, J. J., Chen, P. K., Liu, P., \& Zheng, W. (2002). VEGF expression and enhanced production by gonadotropins in ovarian epithelial tumors. International Journal of Cancer, 97(2), 163-167.

139. Gao, N., Nester, R. A., \& Sarkar, M. A. (2004). 4-Hydroxy estradiol but not 2-hydroxy estradiol induces expression of hypoxia-inducible factor 1alpha and vascular endothelial growth factor A through phosphatidylinositol 3-kinase/Akt/FRAP pathway in OVCAR-3 and A2780-CP70 human ovarian carcinoma cells. Toxicology and Applied Pharmacology, 196(1), 124-135. doi:10.1016/j.taap.2003.12.002.

140. Belotti, D., Paganoni, P., Manenti, L., Garofalo, A., Marchini, S., Taraboletti, G., et al. (2003). Matrix metalloproteinases (MMP9 and MMP2) induce the release of vascular endothelial growth factor (VEGF) by ovarian carcinoma cells: implications for ascites formation. Cancer Research, 63(17), 5224-5229.

141. Xia, C., Meng, Q., Liu, L. Z., Rojanasakul, Y., Wang, X. R., \& Jiang, B. H. (2007). Reactive oxygen species regulate angiogenesis and tumor growth through vascular endothelial growth factor. Cancer Research, 67(22), 10823-10830. doi:10.1158/ 0008-5472.can-07-0783.

142. Gupta, R. A., Tejada, L. V., Tong, B. J., Das, S. K., Morrow, J. D., Dey, S. K., et al. (2003). Cyclooxygenase-1 is overexpressed and promotes angiogenic growth factor production in ovarian cancer. Cancer Research, 63(5), 906-911.

143. Xin, B., Yokoyama, Y., Shigeto, T., Futagami, M., \& Mizunuma, H. (2007). Inhibitory effect of meloxicam, a selective cyclooxygenase2 inhibitor, and ciglitazone, a peroxisome proliferator-activated receptor gamma ligand, on the growth of human ovarian cancers. Cancer, 110(4), 791-800. doi:10.1002/cncr.22854

144. Hu, Y. L., Tee, M. K., Goetzl, E. J., Auersperg, N., Mills, G. B., Ferrara, N., et al. (2001). Lysophosphatidic acid induction of vascular endothelial growth factor expression in human ovarian cancer cells. Journal of the National Cancer Institute, 93(10), 762-768

145. Dutta, S., Wang, F. Q., Wu, H. S., Mukherjee, T. J., \& Fishman, D. A. (2011). The NF-kappaB pathway mediates lysophosphatidic acid (LPA)-induced VEGF signaling and cell invasion in epithelial ovarian cancer (EOC). Gynecologic Oncology. doi:10.1016/j.ygyno.2011.06.006.

146. Zhang, L., Yang, N., Katsaros, D., Huang, W., Park, J. W., Fracchioli, S., et al. (2003). The oncogene phosphatidylinositol 3 '-kinase catalytic subunit alpha promotes angiogenesis via vascular endothelial growth factor in ovarian carcinoma. Cancer Research, 63(14), 4225-4231.

147. Yang, G., Cai, K. Q., Thompson-Lanza, J. A., Bast, R. C., Jr., \& Liu, J. (2004). Inhibition of breast and ovarian tumor growth through multiple signaling pathways by using retrovirus-mediated small interfering RNA against Her-2/neu gene expression. Journal of Biological Chemistry, 279(6), 4339-4345. doi:10.1074/jbc. M311153200.

148. Hennessy, B. T., Coleman, R. L., \& Markman, M. (2009). Ovarian cancer. The Lancet, 374(9698), 1371-1382.

149. Mesiano, S., Ferrara, N., \& Jaffe, R. B. (1998). Role of vascular endothelial growth factor in ovarian cancer: inhibition of ascites formation by immunoneutralization. American Journal of Pathology, 153(4), 1249-1256. doi:10.1016/s0002-9440(10)65669-6.
150. Zhang, L., Yang, N., Park, J. W., Katsaros, D., Fracchioli, S., Cao, G., et al. (2003). Tumor-derived vascular endothelial growth factor up-regulates angiopoietin-2 in host endothelium and destabilizes host vasculature, supporting angiogenesis in ovarian cancer. Cancer Research, 63(12), 3403-3412.

151. Xia, C., Meng, Q., Cao, Z., Shi, X., \& Jiang, B. H. (2006). Regulation of angiogenesis and tumor growth by p110 alpha and AKT1 via VEGF expression. Journal of Cellular Physiology, 209(1), 56-66. doi:10.1002/jcp.20707.

152. Liby, T. A., Spyropoulos, P., Buff Lindner, H., Eldridge, J., Beeson, C., Hsu, T., et al. (2011). Akt3 controls vascular endothelial growth factor secretion and angiogenesis in ovarian cancer cells. International Journal of Cancer. doi:10.1002/ ijc. 26010.

153. Boocock, C. A., Charnock-Jones, D. S., Sharkey, A. M., McLaren, J., Barker, P. J., Wright, K. A., et al. (1995). Expression of vascular endothelial growth factor and its receptors flt and KDR in ovarian carcinoma. Journal of the National Cancer Institute, 87(7), 506-516.

154. Mattern, J., Stammler, G., Koomagi, R., Wallwiener, D., Kaufmann, M., \& Volm, M. (1997). Association of vascular endothelial growth factor expression with tumor cell proliferation in ovarian carcinoma. Anticancer Research, 17(1B), 621-624.

155. Chen, H., Ye, D., Xie, X., Chen, B., \& Lu, W. (2004). VEGF, VEGFRs expressions and activated STATs in ovarian epithelial carcinoma. Gynecologic Oncology, 94(3), 630-635. doi:10.1016/ j.ygyno.2004.05.056.

156. Spannuth, W. A., Nick, A. M., Jennings, N. B., Armaiz-Pena, G. N., Mangala, L. S., Danes, C. G., et al. (2009). Functional significance of VEGFR-2 on ovarian cancer cells. International Journal of Cancer, 124(5), 1045-1053. doi:10.1002/ijc.24028.

157. Sher, I., Adham, S. A., Petrik, J., \& Coomber, B. L. (2009). Autocrine VEGF-A/KDR loop protects epithelial ovarian carcinoma cells from anoikis. International Journal of Cancer, 124 (3), 553-561. doi:10.1002/ijc.23963.

158. Trinh, X. B., Tjalma, W. A., Vermeulen, P. B., Van den Eynden, G., Van der Auwera, I., Van Laere, S. J., et al. (2009). The VEGF pathway and the AKT/mTOR/p70S6K1 signalling pathway in human epithelial ovarian cancer. British Journal of Cancer, 100 (6), 971-978. doi:10.1038/sj.bjc.6604921.

159. Kaplan, R. N., Rafii, S., \& Lyden, D. (2006). Preparing the "soil": the premetastatic niche. Cancer Research, 66(23), 11089 11093. doi:10.1158/0008-5472.can-06-2407.

160. Sawano, A., Iwai, S., Sakurai, Y., Ito, M., Shitara, K., Nakahata, T., et al. (2001). Flt-1, vascular endothelial growth factor receptor 1 , is a novel cell surface marker for the lineage of monocyte-macrophages in humans. Blood, 97(3), 785-791.

161. Hashizume, H., Baluk, P., Morikawa, S., McLean, J. W., Thurston, G., Roberge, S., et al. (2000). Openings between defective endothelial cells explain tumor vessel leakiness. American Journal of Pathology, 156(4), 1363-1380. doi:10.1016/s0002-9440(10)65006-7.

162. Summy, J. M., \& Gallick, G. E. (2003). Src family kinases in tumor progression and metastasis. Cancer and Metastasis Reviews, 22(4), 337-358.

163. Weis, S., Cui, J., Barnes, L., \& Cheresh, D. (2004). Endothelial barrier disruption by VEGF-mediated Src activity potentiates tumor cell extravasation and metastasis. The Journal of Cell Biology, 167(2), 223-229. doi:10.1083/jcb.200408130.

164. Olson, T., Mohanraj, D., \& Ramakrishnan, S. (1996). In vivo neutralization of vascular endothelial growth factor (VEGF) vascular permeability factor (VPF) inhibits ovarian carcinomaassociated ascites formation and tumor growth. International Journal of Oncology, 8(3), 505-511.

165. Zhang, L., Yang, N., Garcia, J. R., Mohamed, A., Benencia, F., Rubin, S. C., et al. (2002). Generation of a syngeneic mouse 
model to study the effects of vascular endothelial growth factor in ovarian carcinoma. American Journal of Pathology, 161(6), 2295-2309.

166. So, J., Wang, F. Q., Navari, J., Schreher, J., \& Fishman, D. A. (2005). LPA-induced epithelial ovarian cancer (EOC) in vitro invasion and migration are mediated by VEGF receptor-2 (VEGF-R2). Gynecologic Oncology, 97(3), 870-878. doi:10.1016/j.ygyno.2005.03.004.

167. Wang, F. Q., So, J., Reierstad, S., \& Fishman, D. A. (2006). Vascular endothelial growth factor-regulated ovarian cancer invasion and migration involves expression and activation of matrix metalloproteinases. International Journal of Cancer, 118 (4), 879-888. doi:10.1002/ijc.21421.

168. Zhang, A., Meng, L., Wang, Q., Xi, L., Chen, G., Wang, S., et al. (2006). Enhanced in vitro invasiveness of ovarian cancer cells through up-regulation of VEGF and induction of MMP-2. Oncology Reports, 15(4), 831-836.

169. Belotti, D., Calcagno, C., Garofalo, A., Caronia, D., Riccardi, E., Giavazzi, R., et al. (2008). Vascular endothelial growth factor stimulates organ-specific host matrix metalloproteinase- 9 expression and ovarian cancer invasion. Molecular Cancer Research, 6 (4), 525-534. doi:10.1158/1541-7786.mcr-07-0366.

170. Wang, J. Y., Sun, T., Zhao, X. L., Zhang, S. W., Zhang, D. F., $\mathrm{Gu}$, Q., et al. (2008). Functional significance of VEGF-a in human ovarian carcinoma: role in vasculogenic mimicry. Cancer Biology \& Therapy, 7(5), 758-766.

171. Naora, H., \& Montell, D. J. (2005). Ovarian cancer metastasis: integrating insights from disparate model organisms. Nature Reviews Cancer, 5(5), 355-366. doi:10.1038/nrc1611.

172. Ziogas, A. C., Gavalas, N. G., Tsiatas, M., Tsitsilonis, O., Politi, E., Terpos, E., et al. (2011). VEGF directly suppresses activation of $T$ cells from ovarian cancer patients and healthy individuals via VEGF receptor type 2. International Journal of Cancer. doi:10.1002/ijc.26094.

173. Ahmed, N., Thompson, E. W., \& Quinn, M. A. (2007). Epithelialmesenchymal interconversions in normal ovarian surface epithelium and ovarian carcinomas: an exception to the norm. Journal of Cellular Physiology, 213(3), 581-588. doi:10.1002/jcp.21240.

174. Shield, K., Ackland, M. L., Ahmed, N., \& Rice, G. E. (2009). Multicellular spheroids in ovarian cancer metastases: biology and pathology. Gynecologic Oncology, 113(1), 143-148. doi:10.1016/j.ygyno.2008.11.032.

175. Carmignani, C. P., Sugarbaker, T. A., Bromley, C. M., \& Sugarbaker, P. H. (2003). Intraperitoneal cancer dissemination: mechanisms of the patterns of spread. Cancer and Metastasis Reviews, 22(4), 465-472.

176. Huynh, H., Teo, C. C. M., \& Soo, K. C. (2007). Bevacizumab and rapamycin inhibit tumor growth in peritoneal model of human ovarian cancer. Molecular Cancer Therapeutics, 6(11), 2959-2966. doi:10.1158/1535-7163.mct-07-0237.

177. Fagotti, A., Gallotta, V., Romano, F., Fanfani, F., Rossitto, C., Naldini, A., et al. (2010). Peritoneal carcinosis of ovarian origin. World Journal Gastrointestinal Oncology, 2(2), 102-108. doi:10.4251/wjgo.v2.i2.102.

178. Chereau, E., Ballester, M., Selle, F., Cortez, A., Darai, E., \& Rouzier, R. (2010). Comparison of peritoneal carcinomatosis scoring methods in predicting resectability and prognosis in advanced ovarian cancer. American Journal of Obstetrics and Gynecology, 202(2), 178 e171-178 e110. doi:10.1016/ j.ajog.2009.10.856.

179. Parsons, S. L., Lang, M. W., \& Steele, R. J. (1996). Malignant ascites: a 2-year review from a teaching hospital. European Journal of Surgical Oncology, 22(3), 237-239.

180. Mackey, J. R., \& Venner, P. M. (1996). Malignant ascites: demographics, therapeutic efficacy and predictors of survival. The Canadian Journal of Oncology, 6(2), 474-480.
181. Wilailak, S., Linasmita, V., \& Srivannaboon, S. (1999). Malignant ascites in female patients: a seven-year review. Journal of the Medical Association of Thailand, 82(1), 15-19.

182. Ayantunde, A., \& Parsons, S. (2007). Pattern and prognostic factors in patients with malignant ascites: a retrospective study. Annals of Oncology, 18(5), 945-949. doi:10.1093/annonc/mdl499.

183. Hirabayashi, K., \& Graham, J. (1970). Genesis of ascites in ovarian cancer. American Journal of Obstetrics and Gynecology, 106(4), 492-497.

184. Byrne, A. T., Ross, L., Holash, J., Nakanishi, M., Hu, L., Hofmann, J. I., et al. (2003). Vascular endothelial growth factortrap decreases tumor burden, inhibits ascites, and causes dramatic vascular remodeling in an ovarian cancer model. Clinical Cancer Research, 9(15), 5721-5728.

185. Pourgholami, M. H., Yan Cai, Z., Lu, Y., Wang, L., \& Morris, D. L. (2006). Albendazole: a potent inhibitor of vascular endothelial growth factor and malignant ascites formation in OVCAR-3 tumor-bearing nude mice. Clinical Cancer Research, 12(6), 1928-1935. doi:10.1158/1078-0432.ccr-05-1181.

186. Senger, D. R., Perruzzi, C. A., Feder, J., \& Dvorak, H. F. (1986). A highly conserved vascular permeability factor secreted by a variety of human and rodent tumor cell lines. Cancer Research, 46(11), 5629-5632.

187. Yeo, K. T., Wang, H. H., Nagy, J. A., Sioussat, T. M., Ledbetter, S. R., Hoogewerf, A. J., et al. (1993). Vascular permeability factor (vascular endothelial growth factor) in guinea pig and human tumor and inflammatory effusions. Cancer Research, 53 (12), 2912-2918.

188. Nagy, J. A., Masse, E. M., Herzberg, K. T., Meyers, M. S., Yeo, K. T., Yeo, T. K., et al. (1995). Pathogenesis of ascites tumor growth: vascular permeability factor, vascular hyperpermeability, and ascites fluid accumulation. Cancer Research, 55(2), 360-368.

189. Luo, J. C., Yamaguchi, S., Shinkai, A., Shitara, K., \& Shibuya, M. (1998). Significant expression of vascular endothelial growth factor/vascular permeability factor in mouse ascites tumors. Cancer Research, 58(12), 2652-2660.

190. Hampl, M., Tanaka, T., Albert, P. S., Lee, J., Ferrari, N., \& Fine, H. A. (2001). Therapeutic effects of viral vector-mediated antiangiogenic gene transfer in malignant ascites. Human Gene Therapy, 12 (14), 1713-1729. doi:10.1089/104303401750476221.

191. Xu, L., Yoneda, J., Herrera, C., Wood, J., Killion, J. J., \& Fidler, I. J. (2000). Inhibition of malignant ascites and growth of human ovarian carcinoma by oral administration of a potent inhibitor of the vascular endothelial growth factor receptor tyrosine kinases. International Journal of Oncology, 16(3), 445-454.

192. Hasumi, Y., Mizukami, H., Urabe, M., Kohno, T., Takeuchi, K., Kume, A., et al. (2002). Soluble FLT-1 expression suppresses carcinomatous ascites in nude mice bearing ovarian cancer. Cancer Research, 62(7), 2019-2023.

193. Dong, W. G., Sun, X. M., Yu, B. P., Luo, H. S., \& Yu, J. P. (2003). Role of VEGF and CD44v6 in differentiating benign from malignant ascites. World Journal of Gastroenterology, 9(11), 2596-2600.

194. Yabushita, H., Shimazu, M., Noguchi, M., Kishida, T., Narumiya, H., \& Sawaguchi, K. (2003). Vascular endothelial growth factor activating matrix metalloproteinase in ascitic fluid during peritoneal dissemination of ovarian cancer. Oncology Reports, 10(1), 89-95.

195. Cormio, G., Rossi, C., Cazzolla, A., Resta, L., Loverro, G., Greco, P., et al. (2003). Distant metastases in ovarian carcinoma. International Journal of Gynecological Cancer, 13(2), 125-129.

196. Akahira, J. I., Yoshikawa, H., Shimizu, Y., Tsunematsu, R., Hirakawa, T., Kuramoto, H., et al. (2001). Prognostic factors of stage IV epithelial ovarian cancer: a multicenter retrospective study. Gynecologic Oncology, 81(3), 398-403. doi:10.1006/gyno.2001.6172.

197. Huang, K. J., \& Sui, L. H. (2011). The relevance and role of vascular endothelial growth factor $\mathrm{C}$, matrix metalloproteinase-2 
and E-cadherin in epithelial ovarian cancer. Medical Oncology. doi:10.1007/s12032-010-9817-4.

198. Ferrara, N., Hillan, K. J., \& Novotny, W. (2005). Bevacizumab (Avastin), a humanized anti-VEGF monoclonal antibody for cancer therapy. Biochemical and Biophysical Research Communications, 333(2), 328-335. doi:10.1016/j.bbrc.2005.05.132.

199. Hu, L., Hofmann, J., Zaloudek, C., Ferrara, N., Hamilton, T., \& Jaffe, R. B. (2002). Vascular endothelial growth factor immunoneutralization plus Paclitaxel markedly reduces tumor burden and ascites in athymic mouse model of ovarian cancer. American Journal of Pathology, 161(5), 1917-1924. doi:10.1016/s00029440(10)64467-7.

200. Mabuchi, S., Terai, Y., Morishige, K., Tanabe-Kimura, A., Sasaki, H., Kanemura, M., et al. (2008). Maintenance treatment with bevacizumab prolongs survival in an in vivo ovarian cancer model. Clinical Cancer Research, 14(23), 7781-7789. doi:10.1158/1078-0432.ccr-08-0243.

201. Wulff, C., Wilson, H., Rudge, J. S., Wiegand, S. J., Lunn, S. F., \& Fraser, H. M. (2001). Luteal angiogenesis: prevention and intervention by treatment with vascular endothelial growth factor trap(A40). Journal of Clinical Endocrinology and Metabolism, 86(7), 3377-3386.

202. Hu, L., Hofmann, J., Holash, J., Yancopoulos, G. D., Sood, A. K., \& Jaffe, R. B. (2005). Vascular endothelial growth factor trap combined with paclitaxel strikingly inhibits tumor and ascites, prolonging survival in a human ovarian cancer model. Clinical Cancer Research, 11(19 Pt 1), 6966-6971. doi:10.1158/1078-0432.ccr-05-0910.

203. Krupitskaya, Y., \& Wakelee, H. A. (2009). Ramucirumab, a fully human $\mathrm{mAb}$ to the transmembrane signaling tyrosine kinase VEGFR-2 for the potential treatment of cancer. Current Opinion in Investigational Drugs, 10(6), 597-605.

204. Spratlin, J. L., Cohen, R. B., Eadens, M., Gore, L., Camidge, D. R., Diab, S., et al. (2010). Phase I pharmacologic and biologic study of ramucirumab (IMC-1121B), a fully human immunoglobulin G1 monoclonal antibody targeting the vascular endothelial growth factor receptor-2. Journal of Clinical Oncology, 28 (5), 780-787. doi:10.1200/JCO.2009.23.7537.

205. Wedge, S. R., Kendrew, J., Hennequin, L. F., Valentine, P. J., Barry, S. T., Brave, S. R., et al. (2005). AZD2171: a highly potent, orally bioavailable, vascular endothelial growth factor receptor-2 tyrosine kinase inhibitor for the treatment of cancer. Cancer Research, 65 (10), 4389-4400. doi:10.1158/0008-5472.CAN-04-4409.

206. Hirte, H. W., Vidal, L., Fleming, G. F., Sugimoto, A. K., Morgan, R. J., Biagi, J. J., et al. (2008). A phase II study of cediranib (AZD2171) in recurrent or persistent ovarian, peritoneal or fallopian tube cancer: final results of a PMH, Chicago and California consortia trial. Journal Clinical Oncology (Meeting Abstracts), 26(15_suppl), 5521.

207. Matulonis, U. A., Berlin, S., Ivy, P., Tyburski, K., Krasner, C., Zarwan, C., et al. (2009). Cediranib, an oral inhibitor of vascular endothelial growth factor receptor kinases, is an active drug in recurrent epithelial ovarian, fallopian tube, and peritoneal cancer. Journal of Clinical Oncology, 27(33), 5601-5606. doi:10.1200/ JCO.2009.23.2777.

208. Holtz, D. O., Krafty, R. T., Mohamed-Hadley, A., Zhang, L., Alagkiozidis, I., Leiby, B., et al. (2008). Should tumor VEGF expression influence decisions on combining low-dose chemotherapy with antiangiogenic therapy? Preclinical modeling in ovarian cancer. Journal of Translational Medicine, 6, 2. doi:10.1186/1479-5876-6-2.

209. Bauerschlag, D. O., Schem, C., Tiwari, S., Egberts, J. H., Weigel, M. T., Kalthoff, H., et al. (2010). Sunitinib (SU11248) inhibits growth of human ovarian cancer in xenografted mice. Anticancer Research, 30(9), 3355-3360.

210. Rauh-Hain, J. A., \& Penson, R. T. (2008). Potential benefit of Sunitinib in recurrent and refractory ovarian clear cell adenocar- cinoma. International Journal of Gynecological Cancer, 18(5), 934-936. doi:10.1111/j.1525-1438.2007.01156.x.

211. Biagi, J. J., Oza, A. M., Grimshaw, R., Ellard, S. L., Lee, U., Sederias, J., et al. (2008). A phase II study of sunitinib (SU11248) in patients (pts) with recurrent epithelial ovarian, fallopian tube or primary peritoneal carcinoma-NCIC CTG IND 185. ASCO Meeting Abstracts, 26(15_suppl), 5522.

212. Matsumura, N., Mandai, M., Okamoto, T., Yamaguchi, K., Yamamura, S., Oura, T., et al. (2010). Sorafenib efficacy in ovarian clear cell carcinoma revealed by transcriptome profiling. Cancer Science, 101(12), 2658-2663. doi:10.1111/j.13497006.2010.01736.x.

213. DeGrendele, H., Chu, E., \& Marshall, J. (2003). Activity of the Raf kinase inhibitor BAY 43-9006 in patients with advanced solid tumors. Clinical Colorectal Cancer, 3(1), 16-18.

214. Azad, N. S., Posadas, E. M., Kwitkowski, V. E., Steinberg, S. M., Jain, L., Annunziata, C. M., et al. (2008). Combination targeted therapy with sorafenib and bevacizumab results in enhanced toxicity and antitumor activity. Journal of Clinical Oncology, 26(22), 3709-3714. doi:10.1200/JCO.2007.10.8332.

215. Matei, D., Sill, M. W., Lankes, H. A., DeGeest, K., Bristow, R. E., Mutch, D., et al. (2010). Activity of sorafenib in recurrent ovarian cancer and primary peritoneal carcinomatosis: a gynecologic oncology group trial. Journal of Clinical Oncology, 29 (1), 69-75. doi:10.1200/JCO.2009.26.7856.

216. Schroder, W., Witteveen, E., Abadie, S., Campone, M., Viens, P., Jalava, T., et al. (2005). A phase IB, open label, safety and pharmacokinetic (PK) study of escalating doses of PTK787/ZK 222584 in combination with paclitaxel and carboplatin in patients (PTs) with stage IIC to IV epithelial ovarian cancer. ASCO Meeting Abstracts, 23(16_suppl), 5042.

217. Wedge, S. R., Ogilvie, D. J., Dukes, M., Kendrew, J., Chester, R., Jackson, J. A., et al. (2002). ZD6474 inhibits vascular endothelial growth factor signaling, angiogenesis, and tumor growth following oral administration. Cancer Research, 62(16), 4645-4655.

218. Annunziata, C. M., Walker, A. J., Minasian, L., Yu, M., Kotz, H., Wood, B. J., et al. (2010). Vandetanib, designed to inhibit VEGFR2 and EGFR signaling, had no clinical activity as monotherapy for recurrent ovarian cancer and no detectable modulation of VEGFR2. Clinical Cancer Research, 16(2), 664672. doi:10.1158/1078-0432.CCR-09-2308.

219. Hilberg, F., Roth, G. J., Krssak, M., Kautschitsch, S., Sommergruber, W., Tontsch-Grunt, U., et al. (2008). BIBF 1120: triple angiokinase inhibitor with sustained receptor blockade and good antitumor efficacy. Cancer Research, 68(12), 4774-4782. doi:10.1158/00085472.CAN-07-6307.

220. Ledermann, J. A., Rustin, G. J., Hackshaw, A., Kaye, S. B., Jayson, G., Gabra, H., et al. (2009). A randomized phase II placebocontrolled trial using maintenance therapy to evaluate the vascular targeting agent BIBF 1120 following treatment of relapsed ovarian cancer (OC). ASCO Meeting Abstracts, 27(15S), 5501.

221. Thaker, P. H., Yazici, S., Nilsson, M. B., Yokoi, K., Tsan, R. Z., He, J., et al. (2005). Antivascular therapy for orthotopic human ovarian carcinoma through blockade of the vascular endothelial growth factor and epidermal growth factor receptors. Clinical Cancer Research, 11(13), 4923-4933. doi:10.1158/1078-0432. CCR-04-2060.

222. Kamat, A. A., Kim, T. J., Landen, C. N., Jr., Lu, C., Han, L. Y., Lin, Y. G., et al. (2007). Metronomic chemotherapy enhances the efficacy of antivascular therapy in ovarian cancer. Cancer Research, 67(1), 281-288. doi:10.1158/0008-5472.CAN-06-3282.

223. Merritt, W. M., Nick, A. M., Carroll, A. R., Lu, C., Matsuo, K., Dumble, M., et al. (2010). Bridging the gap between cytotoxic and biologic therapy with metronomic topotecan and pazopanib in ovarian cancer. Molecular Cancer Therapeutics, 9(4), 985995. doi:10.1158/1535-7163.mct-09-0967. 
224. Friedlander, M., Hancock, K. C., Rischin, D., Messing, M. J., Stringer, C. A., Matthys, G. M., et al. (2010). A phase II, openlabel study evaluating pazopanib in patients with recurrent ovarian cancer. Gynecologic Oncology, 119(1), 32-37. doi:10.1016/j.ygyno.2010.05.033.

225. Polverino, A., Coxon, A., Starnes, C., Diaz, Z., DeMelfi, T., Wang, L., et al. (2006). AMG 706, an oral, multikinase inhibitor that selectively targets vascular endothelial growth factor, platelet-derived growth factor, and kit receptors, potently inhibits angiogenesis and induces regression in tumor xenografts. Cancer Research, 66(17), 8715-8721. doi:10.1158/0008-5472.can-05-4665.

226. Hirte, H. W. (2009). Novel developments in angiogenesis cancer therapy. Current Oncology, 16(3), 50-54.

227. Cook, K. M., \& Figg, W. D. (2010). Angiogenesis inhibitors: current strategies and future prospects. CA: A Cancer Journal for Clinicians, 60(4), 222-243. doi:10.3322/caac.20075.

228. Shojaei, F., Wu, X., Malik, A. K., Zhong, C., Baldwin, M. E., Schanz, S., et al. (2007). Tumor refractoriness to anti-VEGF treatment is mediated by $\mathrm{CD} 11 \mathrm{~b}+\mathrm{Gr} 1+$ myeloid cells. Nature Biotechnology, 25(8), 911-920. doi:10.1038/nbt1323.

229. Gaur, P., Bose, D., Samuel, S., \& Ellis, L. M. (2009). Targeting tumor angiogenesis. Seminars in Oncology, 36(2 Suppl 1), S12S19. doi:10.1053/j.seminoncol.2009.02.002.

230. Paez-Ribes, M., Allen, E., Hudock, J., Takeda, T., Okuyama, H., Vinals, F., et al. (2009). Antiangiogenic therapy elicits malignant progression of tumors to increased local invasion and distant metastasis. Cancer Cell, 15(3), 220-231. doi:10.1016/j. ccr.2009.01.027.

231. Ebos, J. M., Lee, C. R., Cruz-Munoz, W., Bjarnason, G. A., Christensen, J. G., \& Kerbel, R. S. (2009). Accelerated metastasis after short-term treatment with a potent inhibitor of tumor angiogenesis. Cancer Cell, 15(3), 232-239. doi:10.1016/j. ccr.2009.01.021.

232. Ebos, J. M., \& Kerbel, R. S. (2011). Antiangiogenic therapy: impact on invasion, disease progression, and metastasis. Nature Reviews Clinical Oncology, 8(6), 316. doi:10.1038/ nrclinonc.2011.74.

233. Ocana, A., Amir, E., Vera, F., Eisenhauer, E. A., \& Tannock, I. F. (2011). Addition of bevacizumab to chemotherapy for treatment of solid tumors: similar results but different conclusions. Journal of Clinical Oncology, 29(3), 254-256. doi:10.1200/ jco.2010.32.0275.

234. Hayes, D. F. (2011). Bevacizumab treatment for solid tumors: boon or bust? Journal of the American Medical Association, 305 (5), 506-508. doi:10.1001/jama.2011.57.

235. Cohn, D. E., Kim, K. H., Resnick, K. E., O’Malley, D. M., \& Straughn, J. M., Jr. (2011). At what cost does a potential survival advantage of bevacizumab make sense for the primary treatment of ovarian cancer? A cost-effectiveness analysis. Journal of Clinical Oncology, 29(10), 1247-1251. doi:10.1200/jco.2010.32.1075.

236. Hensley, M. L. (2011). Big costs for little gain in ovarian cancer. Journal of Clinical Oncology, 29(10), 1230-1232. doi:10.1200/ jco.2010.34.0489.

237. Burger, R. A., Sill, M. W., Monk, B. J., Greer, B. E., \& Sorosky, J. I. (2007). Phase II trial of bevacizumab in persistent or recurrent epithelial ovarian cancer or primary peritoneal cancer: a Gynecologic Oncology Group Study. Journal of Clinical Oncology, 25(33), 5165-5171. doi:10.1200/JCO.2007.11.5345.

238. Cannistra, S. A., Matulonis, U. A., Penson, R. T., Hambleton, J., Dupont, J., Mackey, H., et al. (2007). Phase II study of bevacizumab in patients with platinum-resistant ovarian cancer or peritoneal serous cancer. Journal of Clinical Oncology, 25 (33), 5180-5186. doi:10.1200/JCO.2007.12.0782.

239. Micha, J. P., Goldstein, B. H., Rettenmaier, M. A., Genesen, M., Graham, C., Bader, K., et al. (2007). A phase II study of outpatient first-line paclitaxel, carboplatin, and bevacizumab for advanced-stage epithelial ovarian, peritoneal, and fallopian tube cancer. International Journal of Gynecological Cancer, 17(4), 771-776. doi:10.1111/j.1525-1438.2007.00886.x.

240. Garcia, A. A., Hirte, H., Fleming, G., Yang, D., Tsao-Wei, D. D., Roman, L., et al. (2008). Phase II clinical trial of bevacizumab and low-dose metronomic oral cyclophosphamide in recurrent ovarian cancer: a trial of the California, Chicago, and Princess Margaret Hospital phase II consortia. Journal of Clinical Oncology, 26(1), 76-82. doi:10.1200/JCO.2007.12.1939.

241. Richardson, D. L., Backes, F. J., Seamon, L. G., Zanagnolo, V., O'Malley, D. M., Cohn, D. E., et al. (2008). Combination gemcitabine, platinum, and bevacizumab for the treatment of recurrent ovarian cancer. Gynecologic Oncology, 111(3), 461466. doi:10.1016/j.ygyno.2008.08.011.

242. Penson, R. T., Dizon, D. S., Cannistra, S. A., Roche, M. R., Krasner, C. N., Berlin, S. T., et al. (2009). Phase II study of carboplatin, paclitaxel, and bevacizumab with maintenance bevacizumab as first-line chemotherapy for advanced mullerian tumors. Journal of Clinical Oncology, 28(1), 154-159. doi:10.1200/JCO.2009.22.7900.

243. Rose, P. G., Drake, R., Braly, P. S., Bell, M. C., Wenham, R. M., Hines, J. H., et al. (2009). Preliminary results of a phase II study of oxaliplatin, docetaxel, and bevacizumab as first-line therapy of advanced cancer of the ovary, peritoneum, and fallopian tube. ASCO Meeting Abstracts, 27(15S), 5546.

244. Brown, J. V., 3rd, Micha, J. P., Rettenmaier, M. A., Abaid, L. N., Lopez, K. L., \& Goldstein, B. H. (2010). A pilot study evaluating a novel regimen comprised of carboplatin, paclitaxel, and bevacizumab for advanced-stage ovarian carcinoma. International Journal of Gynecological Cancer, 20(7), 1132-1136.

245. Tillmanns, T. D., Lowe, M. P., Schwartzberg, L. S., Walker, M. S., \& Stepanski, E. J. (2010). A phase II study of bevacizumab with nab-paclitaxel in patients with recurrent, platinum-resistant primary epithelial ovarian or primary peritoneal carcinoma. ASCO Meeting Abstracts, 28(15_suppl), 5009.

246. Burger, R. A., Brady, M. F., Bookman, M. A., Walker, J. L., Homesley, H. D., Fowler, J., et al. (2010). Phase III trial of bevacizumab (BEV) in the primary treatment of advanced epithelial ovarian cancer (EOC), primary peritoneal cancer (PPC), or fallopian tube cancer (FTC): A Gynecologic Oncology Group study. ASCO Meeting Abstracts, 28(18_suppl). LBA1.

247. McGonigle, K. F., Muntz, H. G., Vuky, J., Paley, P. J., Veljovich, D. S., Greer, B. E., et al. (2011). Combined weekly topotecan and biweekly bevacizumab in women with platinum-resistant ovarian, peritoneal, or fallopian tube cancer: results of a phase 2 study. Cancer, 117(16), 3731-3740. doi:10.1002/cncr.25967.

248. del Carmen, M. G., Micha, J. P., Small, L. A., Street, D. G., Londhe, A., \& McGowan, T. (2011). Pegylated liposomal doxorubicin and carboplatin plus bevacizumab in patients with platinum sensitive recurrent ovarian, fallopian tube, or primary peritoneal cancers: results of a phase II study. ASCO Meeting Abstracts, 29(15_suppl), 5061.

249. Horowitz, N. S., Penson, R. T., Duda, D. G., di Tomaso, E., Boucher, Y., Ancukiewicz, M., et al. (2011). Safety, efficacy, and biomarker exploration in a phase ii study of bevacizumab, oxaliplatin, and gemcitabine in recurrent Mullerian carcinoma. Clinical Ovarian Cancer Other Gynecology Malignant, 4(1), 26-33. doi:10.1016/j.cloc.2011.04.003.

250. Wenham, R., LaPolla, J., Hui-Yi, L., Apte, S., Roberts, W., Lancaster, J., et al. (2011). Phase II trial of docetaxel and bevacizumab in recurrent ovarian cancer within 12 months of prior platinum-based chemotherapy. Gynecologic Oncology, 120 (Supplement 1(0)), S83-S84. doi:10.1016/j.ygyno.2010.12.199.

251. Aghajanian, C., Finkler, N. J., Rutherford, T., Smith, D. A., Yi, J., Parmar, H., et al. (2011). OCEANS: A randomized, doubleblinded, placebo-controlled phase III trial of chemotherapy with 
or without bevacizumab (BEV) in patients with platinumsensitive recurrent epithelial ovarian (EOC), primary peritoneal (PPC), or fallopian tube cancer (FTC). ASCO Meeting Abstracts, 29(15_suppl), LBA5007.

252. Kristensen, G., Perren, T., Qian, W., Pfisterer, J., Ledermann, J. A., Joly, F., et al. (2011). Result of interim analysis of overall survival in the GCIG ICON7 phase III randomized trial of bevacizumab in women with newly diagnosed ovarian cancer. ASCO Meeting Abstracts, 29(15_suppl), LBA5006.

253. Kudoh, K., Takano, M., Kouta, H., Kikuchi, R., Kita, T., Miyamoto, M., et al. (2011). Effects of bevacizumab and pegylated liposomal doxorubicin for the patients with recurrent or refractory ovarian cancers. Gynecologic Oncology, 122(2), 233-237. doi:10.1016/j.ygyno.2011.04.046.

254. O’Malley, D. M., Richardson, D. L., Rheaume, P. S., Salani, R., Eisenhauer, E. L., McCann, G. A., et al. (2011). Addition of bevacizumab to weekly paclitaxel significantly improves progression-free survival in heavily pretreated recurrent epithelial ovarian cancer. Gynecologic Oncology, 121(2), 269-272. doi:10.1016/j.ygyno.2011.01.009.
255. Ojeda, B., Casado, A., Tibau, A., Redondo, A., Beltran, M., Garcia-Martinez, E., et al. (2011). Bevacizumab alone or with chemotherapy in highly pretreated, relapsed, epithelial ovarian cancer patients. ASCO Meeting Abstracts, 29(15_suppl), e15590.

256. Tew, W. P., Colombo, N., Ray-Coquard, I., Oza, A., del Campo, J., Scambia, G., et al. (2007). VEGF-trap for patients (pts) with recurrent platinum-resistant epithelial ovarian cancer (EOC): preliminary results of a randomized, multicenter phase II study. Journal Clinical Oncology (Meeting Abstracts), 25(18_suppl), 5508.

257. Colombo, N., Mangili, G., Mammoliti, S., Kalling, M., Tholander, B., Sternas, L., et al. (2008). Aflibercept (VEGF Trap) for advanced epithelial ovarian cancer (EOC) patients (pts) with symptomatic malignant ascites: preliminary results of a pilot study. Journal Clinical Oncology (Meeting Abstracts), 26(15_suppl), 14598.

258. Coleman, R. L., Duska, L. R., Ramirez, P. T., Modesitt, S. C., Schmeler, K. M., Iyer, R., et al. (2011). Phase II multi-institutional study of docetaxel plus aflibercept (AVE0005, NSC\# 724770) in patients with recurrent ovarian, primary peritoneal, and fallopian tube cancer. ASCO Meeting Abstracts, 29(15_suppl), 5017. 